\title{
Polygamy and child mortality: Historical and modern evidence from Nigeria's Igbo
}

\author{
Vellore Arthi ${ }^{1} \cdot$ James Fenske $^{2}{ }^{2}$
}

Received: 3 May 2016 / Accepted: 8 November 2016 / Published online: 24 November 2016

(C) The Author(s) 2016; This article is published with open access at Springerlink.com

\begin{abstract}
We use historical and modern data on the Igbo ethnic group in Nigeria to assess the relationship between polygamy and child mortality. We examine several possible channels for this correlation, and test its sensitivity to observable characteristics of individuals, households, and regions in order to infer the scope for selection on unobservables to drive the polygamy-child mortality correlation. We find a statistically significant positive relationship between polygamy and child mortality in the modern period, and a statistically insignificant positive relationship in the historical data. Although there is a limited role for polygamist-specific intrahousehold dynamics and behavioral practices in shaping the mortality of children in such households, the sensitivity of the polygamy-child mortality correlation is consistent with an important role for selection into polygamy, particularly on unobservable characteristics.
\end{abstract}

Keywords Polygamy $\cdot$ Child mortality $\cdot$ Family economics

\section{Introduction}

Long of interest to anthropologists and sociologists, the institution of polygamy has also come under study by economists seeking to explain poor development outcomes in Sub-Saharan Africa. In some of these studies, the practice of polygamy has been theorized to hinder economic growth by undermining human capital and wealth

James Fenske

j.fenske@warwick.ac.uk

1 University of Essex, Colchester CO4 3SQ, UK

2 University of Warwick, Coventry CV4 7AL, UK 
accumulation (De La Croix and Mariani 2015; Tertilt 2005); meanwhile others show that the weakening of altruism in polygamous households leads to more efficient production (Akresh et al. 2012, 2016; Kazianga and Wahhaj 2016). These studies suggest that distinct features of polygamous households-or features strongly correlated with polygamy-play an important role in macroeconomic success through their effects on individual wellbeing.

The association between polygamy and poor welfare outcomes is of particular importance given how widespread polygamy is in Sub-Saharan Africa: roughly $25 \%$ of married women in Sub-Saharan Africa are in polygamous marriages, and about the same fraction of children under 14 have been born to polygamous mothers. ${ }^{1}$ Accordingly, it is likely that many of the region's children may be exposed to adverse conditions associated with membership in polygamous households. How does this in turn affect their chances of survival?

In this paper, we analyze the correlation between polygamy ${ }^{2}$ and child mortality in both a historical dataset and a modern one. Our historic data were originally collected in 1911 by the anthropologist Northcote Thomas, in three Igbo villages in southeastern Nigeria. We have recovered these from the archive and digitized them. Using the household rosters that Thomas compiled, we correlate the fraction of the household head's children who have died with his number of wives, and assess the sensitivity of this correlation to controlling for a variety of location and extended family fixed effects, for past fertility, and for the composition of the household. Adding historical data to the literature on polygamy and child health allows us to make two contributions that are not available to many studies that employ modern data. First, we are able to assess the correlation between polygamy and child mortality in a setting where many of the variables that confound the links between child mortality and polygamy in the present, such as Christian religious beliefs or attitudes toward modern medicine, are far less pronounced. In so doing, and in the spirit of Deaton (2009) and Deaton and Cartwright (2016), our approach takes account of how the institutional and historical context may matter to the relationship under study. Second, the historical data classify the households into subvillage quarters and into families, allowing us to assess the strength of the correlation comparing households within these broader networks. Additionally, to our knowledge, ours is the first study to quantitatively test for the relationship between polygamy and child mortality in historical data.

In order to validate our historical findings on the Igbo, and to examine changes in the association between polygamy and child mortality over time in this setting, we perform a similar exercise using the Igbo sub-sample of the most recent Demographic and Health Survey data from Nigeria. We correlate the mortality of individual children with whether their mothers are polygamous, and assess the sensitivity of this correlation to a wide set of controls. In particular, we use methods set forth by Altonji et al. (2005) and Oster (2016) to provide inference on what the sensitivity of our estimates to observable controls can tell us about the

\footnotetext{
1 See appendix for calculation.

${ }^{2}$ In the context of the Igbo in Nigeria, polygamy in fact refers to polygyny, or the practice of one man taking more than one wife. Throughout this paper, we use the two terms interchangeably.
} 
potential role for selection on unobservables to explain the raw correlations that we measure. ${ }^{3}$

In both our historical sample and our modern sample, we find positive correlations between polygamy and child mortality, confirming the stylized fact uncovered in earlier studies (e.g., Omariba and Boyle 2007; Strassmann 1997). In the historic data, however, this result is not statistically significant. ${ }^{4}$ Adding vectors of controls and fixed effects does substantially lower the magnitude of the correlation in the sample, suggesting an important role for selection on both observables and unobservables in explaining the general pattern.

The existing literature has focused on several mechanisms by which polygamy may be associated with poor child health outcomes, including resource dilution, crowding, intra-household allocation, behavioral practices, and selection. Indeed, this literature has reached mixed conclusions as to why and how polygamy correlates with child survival. In order to test the channels by which this association manifests in our data, we consider each of these explanations in turn. Specifically, we include additional controls that either capture the observable drivers of both polygamy and child mortality, or that capture mediating variables that arise as a result of polygamy and that might help explain its correlation with child mortality. Thus, and given the mixed evidence in the literature, a contribution of this paper is first, to confirm the direction of the net association between polygamy and child mortality in the Igbo context, and next, to use this setting to systematically validate the commonly hypothesized mechanisms underlying this relationship. We also focus in much greater depth than in previous studies on how selection into group membership may help explain the adverse association between polygamy and child mortality. Indeed, our study makes selectivity into polygamy the chief focus of the analysis, with findings that suggest that in our context, polygamy as an institutional arrangement may be important only insofar as it proxies a set of regional, household, and individual characteristics that undermine child survival.

To examine the role of resource dilution and physical crowding, we control for several measures of household size and competition between children. We find that the inclusion of these measures increases our estimates of the correlation of polygamy with child mortality. Altonji et al. (2005) tests suggest that these channels would be unlikely to explain away the polygamy-child mortality correlation if we could include all similar unobservables. Oster (2016) tests, by contrast, urge caution: we are able to induce changes in our estimated coefficients that are large relative to the additional variation in mortality explained by these controls.

\footnotetext{
3 We use the term "selection" in the same sense that Heckman (1990, 1979) refers to "self-selection," Altonji et al. (2005) or Oster (2016) refer to "selection on observables/unobservables," and Angrist and Pischke (2009) refer to "selection bias." That is, we consider the degree to which potential mortality outcomes for children of polygamous and non-polygamous parents may differ even if they were assigned the same polygamy status. The variables that might correlate with both polygamy and child mortality, and that confound a causal interpretation of any observed correlation, may not be observable in data. This type of selection can include behavioral selection (e.g., selection into who is polygynous), which can be a form of identification bias. This is distinct from mortality selection, which shapes the properties of a sample of survivors, as in Bozzoli et al. (2009) or Deaton (2007).

4 This is in part because of higher child mortality among the sample of widowers, i.e. men with no current wives. We report additional results excluding widowers in the appendix. Like our main results, these are sensitive to vectors of controls and fixed effects.
} 
We also assess the importance of intra-household allocation in explaining the polygamy-child mortality relationship, first by using gender-specific correlations of polygamy with child mortality, and second, by testing for child mortality differences by wife rank. Here, we find some evidence of a more severe mortality "penalty" for the daughters than for the sons of polygamists in the historical data, evidence which is absent in the modern data. Similarly, in the modern data, where we can observe wife rank, we find no differences in mortality risk for the children of junior vs. senior wives.

To examine differences in the behavioral practices of polygamists which may contribute to child mortality, we measure whether the children of modern polygamists are less likely to receive a broad suite of early-life investments, including vaccinations and medical care in the prenatal period. While these correlations suggest that the children of polygamists receive fewer health investments, a number of these results become statistically insignificant and much smaller in magnitude after controlling for location fixed effects and predetermined controls such as wealth and maternal education. Thus, these results point to selection into polygamy as an important mechanism underlying the polygamy-child mortality relationship.

Finally, we test for the role of differential selection into polygamous unions, and show that several observable characteristics of polygamist parents differ from those of monogamists. No single characteristic so substantially weakens the correlation of polygamy with child mortality that we can identify it as the most important margin of selection. Nevertheless, and in accordance with our findings on behavioral practices, our results on polygamist selectivity are consistent with the importance of unobserved features of the locations where polygamists reside, women's education and opportunities, and general socioeconomic status.

\subsection{Contribution}

\subsubsection{Family form and child outcomes}

There exists a large literature testing how family form and composition affects resource allocation decisions within the household. Factors such as the household's size, age profile, marital type, and kinship type; the gender of decision-makers; and the social status of household members; can affect household outcomes including the types of expenditures made, the distribution of investments amongst members, and the efficiency of household production (Black et al. 2005; Browning 1992; Browning et al. 2014; Duflo and Udry 2004; Grossbard 2014; Kazianga and Wahhaj 2016; Pilla and Dantas 2016; Tertilt 2005).

Recent work has focused on how characteristics and intra-household dynamics peculiar to polygamous households may affect consumption and resource allocation. A key feature of this literature is an examination of the dynamics between wives. For instance, although polygamous households may be intuitively expected to be inefficient, due largely to competition between wives, the evidence is mixed: some studies reject the collective rationality of polygamous households (Dauphin et al. 2015), while others affirm it (Dauphin et al. 2010); yet others find their efficiency to be context-dependent (Dauphin 2013). Agarwal (1997) and Akresh et al. (2012, 2016) emphasize the role of co-wife cooperation in polygamous households, where 
the lack of altruism in co-wife relationships leads to greater productive efficiency between co-wives than between spouses. For contrast, Rossi (2015), Arthi and Fenske (2016), and Kazianga and Klonner (2006) point to co-wife rivalry as a driver of fertility competition amongst polygamist wives, of strategic time mis-allocation in child care, and of health disparities by wife rank, respectively. Meanwhile, Han and Foltz (2015) find that the degree of co-wife competition or cooperation depends on the ethnic context of polygyny. Thus, the balance of power between spouses and amongst wives in polygamous households - and so too, the distribution of resources to children-may depend both on the distinct cultural features of polygamous households, and on selectivity into polygamy by widely-cited determinants of bargaining power such as education, wealth, and outside options.

Investigation of the effects of household composition, through intra-household bargaining, on children's outcomes is a key theme in the work of Angus Deaton. Although some of this research focuses on the effects of household size on per capita food availability (Deaton and Paxson 1998), or offers recommendations to improve the quality of data used to test for age and gender differences in poverty and resource allocation (Case and Deaton 2003), the bulk of this strand of research concerns gender discrimination in intra-household allocation to children. Specifically, Deaton and his co-authors test for such discrimination by using the demographic separability of certain consumption categories to determine the degree to which parents sacrifice their own consumption to accommodate the addition to the household of a son vs. a daughter (Deaton and Muellbauer 1986; Deaton et al. 1989). Using this method, they find suggestive but surprisingly limited evidence of gender discrimination in poor and rural households in Asia and Africa (Deaton 1989; Subramanian and Deaton 1991). Indeed, in response to his own body of research, and a number of similar studies it spawned, Deaton remarks that "it is a puzzle" that expenditure data consistently fails to show gender effects, even where discrimination is known qualitatively to exist, and where outcomes show clear evidence of gender-based differences in welfare (Deaton 1997, p. 240). While the household-level budgetary data typically available may tend to obscure the effects of household composition on resource allocation (Kingdon 2005), it is clear that Deaton's intuition regarding the effects of household form on child well-being remains relevant to studies, such as this and others on the welfare effects of polygamy, which use health outcomes as a revealed measure of parental investment. ${ }^{5}$

Our work adds to this literature by examining how the practice of polygamythrough household organization, features, and behaviors unique to this form of marriage-correlates with child survival. In particular, we show that while there are gender differences in survival in polygamist households, which suggest that these

\footnotetext{
5 Although our data come from Nigeria, the themes it raises-such as resource pressure, gender preference, and intra-household competition in non-nuclear households-are relevant to debates on family form and child health in India, the site of much of Deaton's work, as well as internationally. While polygamy may be primarily practiced in Sub-Saharan Africa, such practices exist both de jure (often in the form of religious exemptions for Muslims) and de facto in a variety of modern societies, including those in the Middle East and South and Southeast Asia. Furthermore, in practice, household dynamics and risks to child health similar to those observed in polygamous households may also exist in nominally monogamous households and in extended or joint ones. For instance, Coffey et al. (2014) find that in rural India, the children of junior-ranked daughters-in-law in joint households achieve lower heights, consistent with nutritional deprivation.
} 
households have either different gender preferences in their offspring or different balances of spousal bargaining power than their monogamist counterparts, there is no evidence of a wife-seniority gradient in child mortality among polygamists. Our finding that polygamy is associated with higher rates of child mortality also suggests that the potential child health benefits of cooperation amongst co-wives may be negligible.

\subsubsection{Income and health in poor settings}

The impact of household form on the distribution of resources to children is of special concern in poor and rural settings, in which the scope to invest in children's nutrition, health care, and education may be limited. Both theory and evidence on childhood poverty and poverty alleviation suggest that children in disadvantaged households suffer worse health and well-being in the short term as well as in later life (Almond et al. 2011; Heckman 2007; Wood 2003). The same may also be the case amongst young children living in poor regions more generally (Chetty et al. 2015; Smith-Greenway and Trinitapoli 2014). Similarly, adverse shocks to household income (e.g., Banerjee et al. 2010; Fishback and Thomasson 2014) and nutritional availability (e.g., Barker and Osmond 1986; Ó Gráda 2011) have been shown to do meaningful damage to children's human capital (see Almond and Currie 2011 for an in-depth survey). Given the prevalence of polygamy in poor and rural regions (Smith-Greenway and Trinitapoli 2014), the selection of poorer and less well educated women into polygamous unions (Amankwaa 1996), and the vulnerability of children in polygamous households to reductions in their access to resources (Brahmbhatt et al. 2002; De La Croix and Mariani 2015), the association between early-life conditions and child health is of particular relevance to our study.

Here, too, Deaton's work offers insights into the relationship between poverty, early-life conditions, and health. This body of research investigates a number of bigpicture issues such as socioeconomic gradients in multi-dimensional health and subjective well-being (Case and Deaton 2005; Deaton 2008b, 2012; Kahneman and Deaton 2010), the impact of income inequality on health (Deaton 2003, 2008a; Deaton and Lubotsky 2003), and the differences within and across countries in the association between improvements in income and those in health (Cutler et al. 2006). However, it also addresses smaller-scale questions such as the degree to which income constrains nutritional provision (Subramanian and Deaton 1996) and the effects of the early-life disease environment on survival and growth (Bozzoli et al. 2009; Deaton 2007).

These latter studies are especially relevant in our context, and emphasize that income likely matters most to nutrition, health, and mortality risk at the lower end of the income distribution. For instance, Deaton (2007) and Bozzoli et al. (2009) find that the adverse effects of the early-life disease environment on adult height in poor settings are so strong that mortality selection (the culling of the health distribution's lower tail), dominates the scarring effects (the damage to individual health status) associated with poverty and early-life morbidity. Their results are especially relevant to our study, since they not only suggest a strong impact of poverty on child health, but also provide a setting in which selection (in their case, into survivorship; in ours, 
into polygamous households) plays an important role in driving the observed health outcomes.

Indeed, our work emphasizes the role of rural poverty in the relationship between Igbo polygamy and child mortality. Firstly, we find that polygamy-which is more prevalent in poor, rural, and socially conservative regions-is associated with poor child survival, suggesting a role for selection into polygamy on the basis of both observable and unobservable characteristics of the places in which this marriage form most often occurs. Secondly, we show that child mortality is higher in polygamist households through the relatively poorer education of polygamist mothers, a characteristic itself associated with poverty and resulting in lower levels of investment in infant health. Thus, we show that the selection of poorer and less well educated women into polygamy is also an important factor underlying the polygamychild mortality correlation. Together, our results contribute to the literature on polygamy and child mortality by suggesting that selection may play an important part in explaining the correlation between the two, particularly on the unobservable characteristics of individuals, households, and the communities from which polygamists are drawn.

The rest of the paper proceeds as follows. In section 2, we discuss the literature on Igbo polygamy and child mortality, and enumerate the channels identified in the literature for the general correlation between polygamy and child mortality. Section 3 describes our sources of historical and modern data. In section 4, we outline both our approaches to analyzing the modern and historical data, as well as the techniques we use to assess the mechanisms driving the polygamy-child mortality relationship and the sensitivity of our results to observed and unobserved variables. These results and sensitivity analyses are presented in sections 5 and 6. Section 7 concludes.

\section{Background}

\subsection{Igbo polygamy}

In this study, we use data on the Igbo ethnic group of Nigeria, amongst whom polygamy is prevalent. The Igbo are the third-largest ethnic group in Nigeria. During the early twentieth century, the Igbo lived largely in rural communities in Southeastern Nigeria with populations ranging from a few hundred to a few thousand (Gailey 1970, p. 23). The Igbo are known for their "stateless" political system, and Igbo agriculture centers on the cultivation of yams and palm oil (Martin 2006). In the 2013 Individual Recode of the Demographic and Health Surveys, a nationally representative sample of Nigerian women aged 15-49, $68 \%$ of Igbo respondents report living in urban areas. $34 \%$ report not working, $28 \%$ report working in sales, and $15 \%$ state that they are agricultural employees. For these women's partners, the most commonly reported occupational categories are skilled manual (28\%), sales (24\%), and agricultural employee $(21 \%)$.

Historically, Igbo marriage was polygynous, patrilocal, and involved the payment of bride price. Polygamy was considered the norm for the Igbo-with Ukaegbu (1977) reporting that $34 \%$ of Igbo women in his sample were polygamous-and men commonly aspired to have multiple wives (Basden 1921, p. 97). Colonial-era 
anthropologists viewed 3 to 5 wives as the most common number for a married man, and the wealthiest and most powerful men could have more than a hundred wives (Basden 1921, p. 99). Thomas (1913) reported that marriage for women occurred as early as at age 9 and as late as at age 16, "or even older." Indeed, Basden (1921, p. 101) worried that, by creating age gaps in marriage and a large population of unmarried men, polygamy encouraged adultery and facilitated the spread of disease, a concern shared by (Uchendu 1965, p. 86).

Anthropologists described several possible motivations for Igbo polygamy during the colonial and early independence periods. Wives were considered to be both sensible investments and indicators of a man's social standing (Basden 1921, p. 97). More recently, Nwoye (2007) has classified motivations for polygamy as being either "affluent" (for example, a wealthy man taking multiple wives) or "interventive" (for example, a man taking a widow as a wife as a means to provide for her care).

For men, polygamy mitigated the impact of household health shocks and conflict, allowing a man to eat when one wife was sick or refused to cook for him (Basden 1921, p. 100). Having a rival in the household could also make a wife more submissive (Egboh 1972, p. 434). Even so, violence today is common within Igbo households and is correlated positively with polygyny (Ilika 2005; Okemgbo et al. 2002).

Perhaps of greatest importance to a polygamous man, the presence of multiple wives allowed for the production of many offspring (Okonjo 1975, p. 23), although according to Ukaegbu (1977), polygynous women could be less fertile because of the age gaps with their husbands. The practice of long birth intervals and post-partum sex taboos may also have motivated polygamy (Basden 1921, p. 98).

Women also supported polygamy (Basden 1921, p. 97). An Igbo woman's marriage to a polygamist was a sign of his, and so too of her, socioeconomic status. Polygamy could also be a source of intra-household power: a junior wife would be bound to honor a senior wife who helped her husband pay the junior wife's bride price (Leith-Ross 1965, p. 126). Women saw the position of sole wife as humiliating, and encouraged their husbands to take on additional wives both for companionship and to provide supplementary labor (Basden 1921, p. 99, 1938, p. 231). While men could hire additional servants to help their wives with their work (Leith-Ross 1965, p. 226), the support of additional wives provided women the freedom to engage in private trading (Uchendu 1965, p. 85).

Polygamous Igbo households were arranged in "matrifocal units," which colonialera anthropologists noted were remarkably autonomous within the family. Different wives lived separately from their husbands, albeit within the same compound (Amadiume 1987, p. 91). After her first birth, a woman would not cohabit with her husband (Basden 1921, p. 99). Husbands and wives often had different interests and household responsibilities, and men were excluded from women's leisure activities (Uchendu 1965, p. 86). To colonial observers, divorce was common (Ottenberg 1982, p. 50). Women could return to their natal families, who would welcome their children (Henderson 1972, p. 216).

These "matrifocal units" existed relatively separately. Each wife had her own "hut;" This helped limit conflicts between these sub-household units (Uchendu 1965, p. 188). The Igbo cooking and eating unit centered on a mother, her children, and other dependents (see Okere et al. 1979, p. 68; Uchendu 1965, p. 55). A wife without children might be unwilling to feed the child of a co-wife, while the children of 
different co-wives could grow up independently and have nothing to do with each other as adults (Henderson and Henderson 1966, p. 48). In fact, mothers often encouraged their children to dislike their half-siblings and to fight with them (Henderson 1972, p. 412).

Clear distinctions existed between wives. A senior wife enjoyed superior legal status that also came with ceremonial privileges (Basden 1921, p. 97). Practically speaking, she was dominant within the household, having substantial control over the other wives (Basden 1921, p. 98).

Conflicts were frequent among co-wives, and centered on their relative importance, their wealth, or over their fertility (Henderson 1969, p. 190). Sororal polygamy was rare, since it could cause disagreement between the sisters (Henderson 1969, p. 169). Because of these frequent and sometimes severe conflicts between co-wives, the mother of the principal heir might send him to live with friends in order to ensure his safety (Basden 1921, p. 102). Despite these disagreements, co-wives could cooperate, particularly in order to compel their husband to follow their will (Uchendu 1965, p. 86).

Whether because of or in spite of the prevalence of polygamy, Igbo society has long been characterized by high child mortality. In the earliest years for which they report data, the Institute for Health Metrics and Evaluation gives a child mortality rate of $22.4 \%$ for Nigeria in $1970,{ }^{6}$ while the World Development Indicators lists a rate of $32.8 \%$ in $1964 .^{7}$ Hauck (1963) reports a number of child mortality estimates from Southeastern Nigeria and the Niger Delta made during the 1950s. These ranged from 20.0 to $40.8 \%$, while her own two study villages gave rates of 50.4 and $42.7 \%$. In the 2013 Demographic and Health Survey, in which women are asked their complete birth histories, $12 \%$ of Igbo children were reported to have died in the first five years of life. For comparison, the World Development Indicators lists a rate of $8.3 \%$ for Sub-Saharan Africa in 2015 and $26.0 \%$ in 1966, compared with 0.7 and $5.9 \%$ for the OECD countries.

Several factors contribute to the high rate of child mortality among the Igbo. Igbo women face an expectation of high fertility (Ebigbo and Chukudebelu 1979; Ukaegbu 1977), and often fail to use family planning technologies (Lucas and Ukaegbu 1977). Uche (1985) cites technological factors such as a lack of clean water, toilet facilities, and modern medicine, as hazards to children's health. Meanwhile, the traditional practice of leaving children in the care of other children may also have endangered child health (Basden 1938; Green 1964). Igbo sociocultural values, such as a belief in "ogbanje" (children who come and go), may also contribute to child mortality by affecting the response to illness and demand for medical treatment (Asakitikpi 2008; Izugbara 2000; Nzewi 2001). Indeed, in our historical sample, the practice of twin infanticide is especially relevant (Achebe 1958; Thomas 1913; Uchendu 1965).

\subsection{Polygamy and child mortality}

A large literature has found correlations between polygamy, poor child health, and increased child mortality in several African contexts (e.g., Amey 2002; Defo 1996;

\footnotetext{
6 www.healthdata.org

7 http://databank.worldbank.org
} 
Gyimah 2003; Wagner and Rieger 2015), with a risk profile that may vary by child age (Gyimah 2009; Ukwuani et al. 2002). Omariba and Boyle (2007) review the literature on the link between polygamy and child mortality; the candidate mechanisms they describe can be broadly classified into resource dilution, crowding, intra-household allocation, behavioral practices, and selection.

\subsubsection{Resource dilution}

While polygamous men tend to be wealthier, Omariba and Boyle (2007) note that the per-capita resources available for a polygamist's wife and children are typically reduced with each additional wife. This is a mechanism emphasized in some theoretical treatments of polygamy (e.g., De La Croix and Mariani (2015)). The empirical evidence for this channel is, however, mixed. Gibson and Mace (2007), for example, find no evidence that polygamous women have lower BMI than monogamous women in Ethiopia, while Sellen (1999) finds clear evidence of growth disadvantage in the children of Tanzanian polygamists. Where women and children are responsible for their own food and subsistence, the dilution of a husband's resources across multiple wives may be minor (Desai 1992). While children of polygamists may face no nutritional disadvantage, they do suffer from lower levels of investment in health care, since these expenditures are typically borne by fathers (Gage 1997).

\subsubsection{Crowding}

The larger size of polygamous households may also result in the problem of physical crowding. In other, non-polygamous, contexts, overcrowding has been found, through disease transmission and poor sanitary conditions, to result in a variety of adverse outcomes including lower heights, higher rates of infectious disease and infant mortality, and poorer academic performance (Bailey et al. 2016; Cage and Foster 2002; Cebu Study Team 1992; Delaney et al. 2011; Duquette 2014; Elender et al. 1998; Eli 2015; Ferreira et al. 2001; Goux and Maurin 2005; Williamson 1982). As in these contexts, the greater number of individuals in a polygamous family-and especially, the greater concentration of young children in such families-has been found to facilitate the spread of and intensification of exposure to infectious diseases such as measles. However, these effects may be offset by greater birth spacing by polygamists relative to monogamists, and by differences amongst polygamous households in the spatial organization of the living compound (Aaby et al. 1983a, b, 1984; Garenne and Aaby 1990).

\subsubsection{Intra-household allocation}

In contrast to resource dilution, which refers only to the mechanical fact that resources per capita are likely to be lower in polygamous households due to their larger size, intra-household allocation-based explanations of the polygamy-child mortality relationship stress how differences in the preferences and power dynamics of monogamous and polygamous households can lead them to allocate the same set of resources differently. Building on Strassmann (1997), who finds greater child mortality among even wealthier polygamists in Mali, Omariba and Boyle (2007) emphasize that male 
polygamists may feel less attachment to or face fewer incentives to invest in any one child, leading to lower levels of human capital investment (Tertilt 2005) and lower chances of social mobility (De La Croix and Mariani 2015) for their children.

Alternatively, the health disadvantage faced by children in polygamous households may stem from the fact that polygamy generally correlates negatively with female bargaining power (Doepke et al. 2012; Tertilt 2005), and that the presence of multiple wives allows for further competition for influence over resource allocation. The children of senior wives often do better (e.g., Gibson and Mace (2007); Kazianga and Klonner (2006))—potentially because these women have the opportunity to spend a portion of their marriage as a monogamist, or because they enjoy greater control over household resources than do junior wives (whether because of the higher regard afforded to first wives culturally, or because first wives are less negatively selected into polygamy relative to later-married wives). Wives in polygamist households may also have lower levels of bargaining power due to their own worse health relative to monogamist women (Bove and Valeggia 2009). Similarly, Brahmbhatt et al. (2002) find that it is only the children of HIV-positive polygamist wives who are at a greater risk of mortality, possibly because resources are diverted away from their children.

\subsubsection{Behavioral practices}

Omariba and Boyle (2007) point out that polygamists may be less open than monogamists to modern medical treatments, due in part to their rural status, limited participation in the formal economy, and low levels of literacy and education. Other relevant behaviors common in polygamous households relative to monogamous ones include un-supplemented breastfeeding (Amankwaa 1996), reduced health-seeking behaviors (Stephenson et al. 2006), and maternal time constraints (Hadley 2005). These (often harmful) child health practices result from customs specific to polygamous households, as well as from the selection of less well educated women into polygamous unions.

\subsubsection{Selection}

The observed and unobserved characteristics of polygamists may drive the correlation between polygamy and child mortality. Omariba and Boyle (2007) note maternal age, female decision-making authority, and financial resources as possible dimensions of selection. Other writers cite the low levels of education of polygamists relative to monogamists (Amankwaa 1996; Gyimah 2003) and the prevalence of polygamy in poorer and less gender-equal regions (Smith-Greenway and Trinitapoli 2014) as important factors underlying the polygamy-child health relationship. Similarly, men may select into polygamy based on whether they favor a "parenting," high-investment strategy over a "mating," low-investment approach (Heath and Hadley 1998). Meanwhile, even within polygamous households, selectivity by wife rank - for instance, by age or socioeconomic status at the time of marriage - may drive intra-household gradients in child outcomes (Gibson and Mace 2007).

Apart from these possible negative influences, the literature has nevertheless emphasized a number of channels that might mitigate or reverse the adverse link between polygamy and child mortality. For instance, some features of polygamy, such as the tendency for larger birth spacing, may contribute to better infant health 
through longer durations of breastfeeding and by limiting the scope for overcrowding in the young age ranges (Aaby et al. 1983a). Similarly, Omariba and Boyle (2007) cite co-wife cooperation as a potential benefit to child health in polygamous households.

\section{Data}

\subsection{Historical data}

The historical data that we use were originally collected between March and May 1911 by the anthropologist Northcote Whitridge Thomas (1868-1936) for use in his report on the Igbo (Thomas 1913). Thomas published summary statistics for these data in the second chapter of the first volume of his report, in which he refers to the three samples as Agolo, Agolo (Ododoma) and Agolo-Awka. His approach was to summon the men of a quarter, question them, and record their answers. Ages of the household members were estimated during a followup visit one month later.

The Department of Manuscripts and University Archives at Cambridge houses the field notes underlying Thomas's report. We use this source of detailed raw data to assess the statistical significance of the correlation between polygamy and child mortality, as well as its sensitivity to additional controls and definitions. Among these field notes are three files (Haddon [11,005], Haddon [11,006], and Haddon [11,007]) which contain raw data cards that, to our knowledge, we are the first to have digitized.

Figure 1 presents an example data card and demonstrates the historical variables available to us in this study. In addition to the information contained on each card, we know the sub-sample from which the family is drawn: the 1215 initial observations are divided across the towns of Agolo (676), Agolo-Awka (177), and Angulu (362), and these are further subdivided into 11 Quarters and 44 Families. The name of the household head, who was typically male, is also listed.

In addition to this information, the card reports the total number of wives, male children, and female children of the household head. These are then divided into those living and dead. Other individuals living in the household are also listed, sometimes with information on how they are related to the family. The total number of individuals living in the house is also given.

The composition of the household is reported by gender (denoted $\$$ or $\delta$ ), and by age categories A (0-2), B (2-15), C (15-20) and D (20+). Although the names of those living in the household are sometimes given, the data do not specifically report which individuals belong to which age category.

In order to test for the relationship between polygamy and child mortality, we restrict our analysis to male-headed households in which the head is currently, or was at some point in the past, married, and in which the head has had children. Restricting the sample to male-headed households (that is, those for whom we can measure polygamy) reduces the sample to 1105 households. Further restricting the sample to those who were ever married reduces the sample to 748 households. Finally, keeping only those men who have had children (that is, those for whom we can compute child mortality) leaves a regression sample of 639 households. 


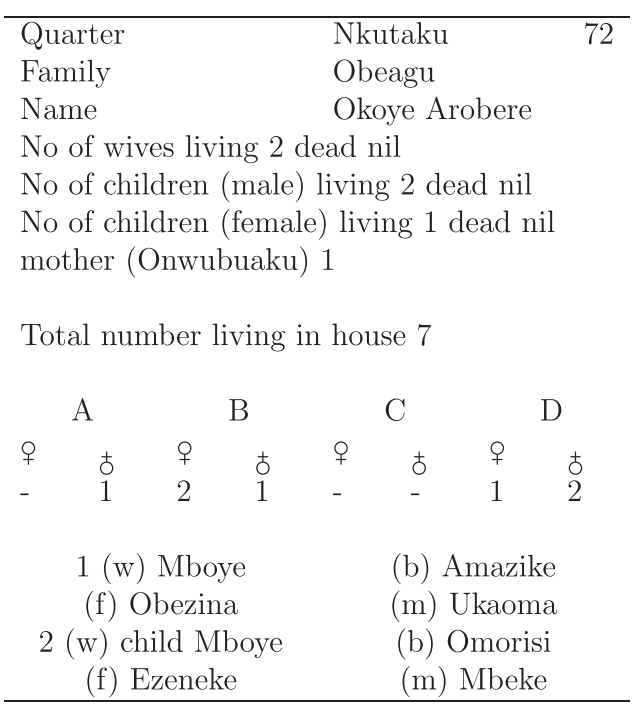

Fig. 1 A typical card

Table 1 presents summary statistics for this historical sample. Of the ever-married male heads, $8 \%$ are currently married, $72 \%$ are monogamists, and $20 \%$ are polygamists (i.e., have more than one wife). ${ }^{8}$ This measure of polygamy will be an underestimate. For example, a bigamist whose second wife has died will be counted as a monogamist by this measure. By contrast, counting polygamy by whether a man's total number of living and dead wives has exceeded one over his lifetime gives a male polygamy rate of $37 \%$. This will be an overestimate, since it will count as a polygamist a monogamist widower or divorcee who subsequently remarried monogamously. Because this latter measure may be correlated with child mortality for reasons other than polygamy itself (for example, the death of a mother in childbirth, or the stress placed on a household by divorce) we do not use it for our analysis.

On average, $44 \%$ of a man's children have died in this historical sample. This will be greater than the true rate of child mortality, since we do not know the age at which these children died, and so deaths above age five will count towards this child mortality measure. A child mortality rate of $44 \%$ is not, however, inconsistent with the other observations cited above from historical Nigeria.

Figure 2 reports means for the fraction of a respondent's children who have died, stratified by polygamy as measured using current living wives. The mortality of children is modestly higher among polygamists (47.4 vs. $43.1 \%$ ), but not statistically significantly so $(t=1.41)$. A similar pattern is visible when presenting means based on a more disaggregated count of wives.

It is clear that the lack of a statistically significant difference between polygamists and monogamists may be driven by widowers, who have no living wives and an unusually large fraction of deceased children. In appendix Table 10, we show all of

\footnotetext{
${ }^{8}$ Because the data do not ask about divorce, we are compelled to treat a man as "ever-married" if he reports having at least one living or dead wife.
} 
Table 1 Summary statistics: historical data

\begin{tabular}{llllll}
\hline & $(1)$ & $(2)$ & $(3)$ & $(4)$ & $(5)$ \\
& Mean & SD & Min & Max & $N$ \\
\hline Polygynous & 0.20 & 0.40 & 0 & 1 & 748 \\
0 wives & 0.080 & 0.27 & 0 & 1 & 748 \\
1 wife & 0.72 & 0.45 & 0 & 1 & 748 \\
2 wives & 0.13 & 0.34 & 0 & 1 & 748 \\
3 wives & 0.028 & 0.17 & 0 & 1 & 748 \\
4+ wives & 0.033 & 0.18 & 0 & 1 & 748 \\
Fraction children dead & 0.44 & 0.32 & 0 & 1 & 639 \\
Total & 5.36 & 4.17 & 0 & 55 & 748 \\
\hline
\end{tabular}
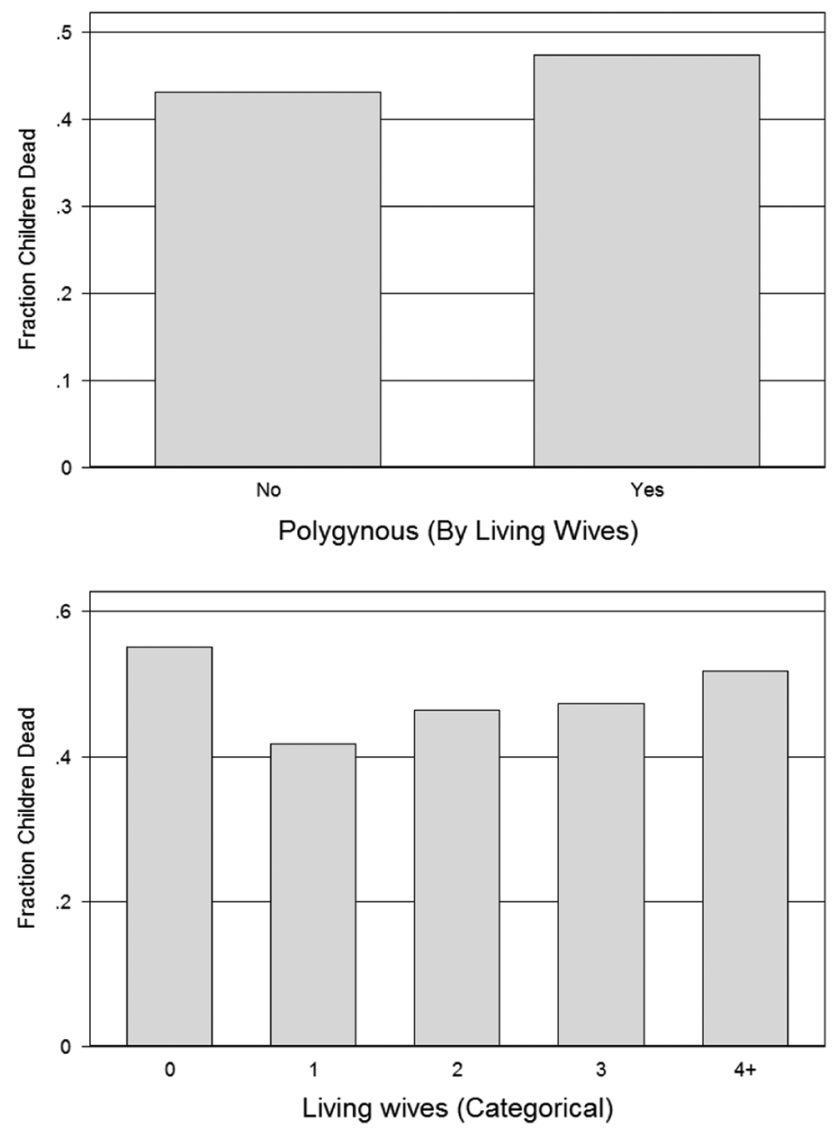

Fig. 2 Polygamy and child mortality: historical data

our results for the historic sample excluding the subsample of widowers with no current wives. These are largely similar in magnitude, statistical significance, and sensitivity to controls, to the results including men with no current wives, excepting that the unconditional correlation between polygamy and child mortality is 
significant at the $5 \%$ level (column (1)). Within the sub-sample of men who have been married but report no current living wives, there is a lower child mortality rate among those who report only having one dead wife $(50.6 \%)$ than those who report having more $(68.8 \%)$, a difference that is statistically insignificant $(t=1.52)$.

\subsection{Modern data}

To compare our historical results with the polygamy-child mortality relationship found in modern data, we rely on the Demographic and Health Survey (DHS). The DHS data have been gathered in multiple developing countries since the mid-1980s. For Nigeria, we use datasets from the most recent wave, conducted in 2013. The base of these data are the individual recodes, which are surveys of women between the ages of 15 and 49. These recodes form a representative national cross-section, and contain many variables that we use in this study, including a woman's year of birth, her education level, whether she lives in a rural area, her occupation, the occupation of her partner, and whether she is in a polygamous marriage. Most importantly to our study, women are also asked their complete birth histories in the births recodes portion of the survey. Whereas in our historical approach, households are the unit of analysis, here in the modern data, these births form our principal unit of observation. From these births data, we use the child's year of birth, birth order, an indicator of multiple birth, gender, and length of the child's life. Lastly, to test whether investments in children differ between polygamous and monogamous households, we use the child recodes. Similar to the birth recodes, but containing a richer set of information on a smaller number of children, these data provide variables pertaining to births in the previous five years. These include whether children were vaccinated or received medical care, the circumstances of the birth, and whether children were breastfed.

We restrict the data to births to Igbo mothers, which leaves a sample of 13,131 births. We can compute the polygamist status for 11,295 of them, based on whether the corresponding mother states that her husband has more than one wife. Summary statistics for this modern sample are presented in Table 2. On average, $12 \%$ of these children died in the first five years of life, and $14 \%$ were born to polygamous mothers. As in the historical data, polygamy largely presents as bigamy, with fewer than $5 \%$ of children born to a woman whose husband has three or more wives.

Figure 3 reports means for child mortality, stratified by polygamy. The mortality of children is clearly higher among polygamists (18.8 vs. $10.8 \%$ ), and the difference is statistically significant at conventional levels $(t=9.22)$. A similar pattern is apparent when comparing children by counts of wives.

\section{Empirical strategy}

\subsection{Historical data}

In the historical data, we describe the correlation of polygamy with child mortality by using ordinary least squares (OLS) to estimate the following regression on our 
Table 2 Summary statistics: modern data

\begin{tabular}{|c|c|c|c|c|c|}
\hline & (1) & (2) & (3) & (4) & $(5)$ \\
\hline & Mean & $\mathrm{SD}$ & Min & $\operatorname{Max}$ & $N$ \\
\hline Child died in first 5 years & 0.12 & 0.32 & 0 & 1 & 11,295 \\
\hline Polygynous & 0.14 & 0.35 & 0 & 1 & 11,295 \\
\hline 1 wife & 0.86 & 0.35 & 0 & 1 & 11,295 \\
\hline 2 wives & 0.097 & 0.30 & 0 & 1 & 11,295 \\
\hline 3 wives & 0.022 & 0.15 & 0 & 1 & 11,295 \\
\hline $4+$ wives & 0.023 & 0.15 & 0 & 1 & 11,295 \\
\hline Child multiple & 0.041 & 0.20 & 0 & 1 & 11,295 \\
\hline Child female & 0.48 & 0.50 & 0 & 1 & 11,295 \\
\hline Year of birth & 2002 & 7.90 & 1976 & 2013 & 11,295 \\
\hline Mother age & 37.5 & 7.49 & 16 & 49 & 11,295 \\
\hline Mother age squared & 1460 & 550 & 256 & 2401 & 11,295 \\
\hline Education in single years & 8.13 & 4.67 & 0 & 19 & 11,288 \\
\hline Wealth index & 0.027 & 0.091 & -0.17 & 0.26 & 11,295 \\
\hline Age of head & 49.5 & 12.4 & 18 & 95 & 11,295 \\
\hline Age of head squared & 2600 & 1318 & 324 & 9025 & 11,295 \\
\hline Cluster number & 555 & 115 & 9 & 890 & 11,295 \\
\hline Number of household members (listed) & 6.23 & 2.52 & 1 & 28 & 11,295 \\
\hline Age at first cohabitation & 19.6 & 4.79 & 10 & 43 & 11,295 \\
\hline Partner completed primary & 0.90 & 0.30 & 0 & 1 & 11,287 \\
\hline Literate & 0.55 & 0.50 & 0 & 1 & 11,255 \\
\hline Urban & 0.66 & 0.47 & 0 & 1 & 11,295 \\
\hline
\end{tabular}

sample of households:

$$
\text { FractionDied }_{i}=\text { BHHPolygamous }_{i}+x_{i}^{\prime} \gamma+\alpha_{j}+\epsilon_{i}
$$

Here, FractionDied Fis $_{i}$ the fraction of children in household $i$ who have died. The

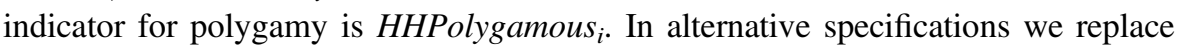
this indicator with a set of dummies for the head's number of wives. $x_{i}$ is a vector of controls. In the baseline this will include only a constant, but when assessing the possible mechanisms that might explain the correlation, we will add additional controls and assess the sensitivity of $\beta$ to these confounders. $\alpha_{j}$ is a vector of fixed effects for town, quarter, or family, depending on the specification. $\epsilon_{i}$ is error. We report standard errors robust to heteroscedasticity.

\subsection{Modern data}

In the modern data, we similarly use OLS on our sample of children ever born to Igbo mothers to estimate:

$$
\text { Died }_{i}=\text { OMotherPolygamous }_{i}+x_{i}^{\prime} \lambda+\phi_{j}+\varepsilon_{i}
$$



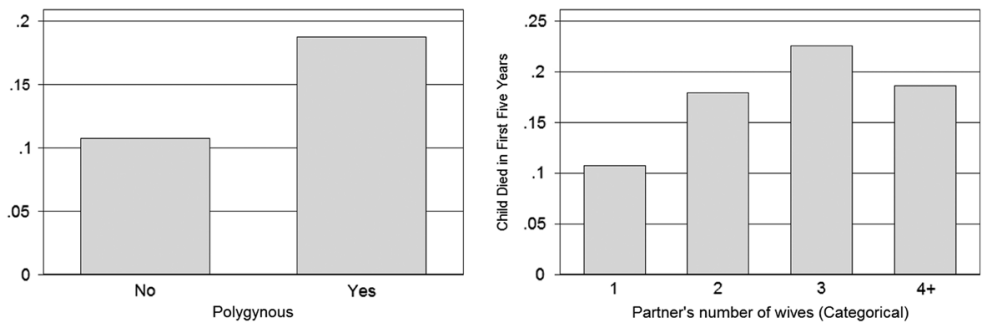

Fig. 3 Polygamy and child mortality: modern data

Here, Died $_{i}$ is an indicator for whether child $i$ died before five years of age. The variable MotherPolygamous M $_{i}$ is an indicator for whether the child's mother reports that her husband has more than one wife. $x_{i}$ is a vector of controls. In the baseline this includes a constant, a dummy for a multiple birth, a dummy for female, the child's year of birth, mother's age and mother's age squared, head's age and head's age squared, mother's years of education, and a wealth index reported in the DHS data, which aggregates the household's durable goods ownership using factor analysis. ${ }^{9} \phi_{j}$ is a vector of fixed effects for survey clusters, which roughly approximate villages or neighborhoods within cities. $\varepsilon_{i}$ is error. We report standard errors clustered by primary sampling unit (PSU), which in the DHS data is equivalent to the survey cluster.

Due to the differences in the historical and modern specifications, which are in turn due to differences in the format and detail of each dataset, we are cautious when making comparisons between the two sets of results. For instance, since the historical data do not contain details of a child's age at death, the relationship between polygamy and child mortality may appear weaker in the historical than in the modern specifications if mortality above age 5 is not as strongly associated with polygamous households. Similarly, as mentioned above in Section 3.1, the most reliable measures in the historical data will underestimate the extent of polygamy, leading to weaker associations in this period. Despite these limitations, it is useful to examine these data side-by-side, and to investigate the historical relationship between polygamy and child mortality among the Igbo, since modern data may be confounded by more recent changes in religious practice and access to public health services.

\subsection{Assessing mechanisms}

Because the variation we observe in polygamy status may not be exogenous, we are unable to make causal claims about the relationships we uncover between polygamy and child mortality. However, the literature in section 2 does suggest a number of variables that can be treated as potential confounders of the polygamy-child mortality relationship (i.e., variables that drive both polygamy and child mortality, giving rise

\footnotetext{
9 The wealth index is a unit-free aggregation of a household's assets. Assets that correlate negatively with wealth, such as a traditional pit latrine, can receive negative weights in the index. Hence, this index can take negative values.
} 
to a spurious relationship between the two), or as possible mediators of it (i.e., variables that arise because of polygamy and that affect child mortality, explaining the channels through which polygamy operates). For the potentially confounding and mediating variables we are able to observe, we use two techniques to assess the degree to which they, and unobserved variables like them, account for the correlation between polygamy and child mortality.

First, we compute Altonji et al. (2005) ratios. Following the approach taken by Bellows and Miguel (2009), we compare estimates of $\beta$ obtained with a full set of controls $\left(\hat{\beta}_{F C}\right)$ to those obtained with a restricted set of controls $\left(\hat{\beta}_{R C}\right)$ :

$$
A E T=\frac{\hat{\beta}_{F C}}{\hat{\beta}_{R C}-\hat{\beta}_{F C}}
$$

If the estimate of $\beta$ with full controls is large relative to the change in the coefficient estimate due to adding these additional controls, this suggests that the correlation is not sensitive to these controls, and that other unobservables similar to those controls that have been included are unlikely to push $\beta$ to zero. The same test is used to assess the sensitivity of $\theta$ to controls. Put more simply, the larger the value of AET (for Altonji Elder Taber), the less likely it is that selection on unobservables drives the estimated relationship between polygamy and child mortality.

Second, we compute Oster (2016) $\delta$ statistics. Oster (2016) considers a general regression model where:

$$
Y=\beta X+\Psi w^{o}+W_{2}+\epsilon .
$$

Here, $Y$ is an outcome of interest, $X$ is a treatment of interest, $w^{o}$ is a vector of observed controls, and $\Psi$ is its associated set of coefficients. $W_{2}$ is an index of unobserved variables. Oster (2016) defines $W_{1}=\Psi w^{\circ}$, and the proportional selection relationship as $\delta\left(\operatorname{Cov}\left(W_{1}, X\right)\right) /\left(\operatorname{Var}\left(W_{1}\right)\right)=\left(\operatorname{Cov}\left(W_{2}, X\right)\right) /\left(\operatorname{Var}\left(W_{2}\right)\right)$, i.e., the degree to which selection on observables is less than or greater than selection on unobservables, as captured by the parameter $\delta$. Oster (2016) then solves for the $\delta$ that corresponds to a treatment effect of $\beta=0$. This parameter is a function of several statistics computed from the data. Critical among these are the coefficients obtained by regressing $Y$ on $X$ with and without controls; the $R^{2}$ values computed by regressing $Y$ on $X$ with and without controls; and $R_{\max }$, the theoretical maximum $R^{2}$ that could be achieved by regressing $Y$ on $w^{o}$ and $W_{2}$. Oster (2016) suggests setting $R_{\max }=1$ and adopting $\delta>1$ (that is, selection on unobservables must be at least as large as selection on observables to yield a treatment effect of 0 ) as a heuristic. We adopt these conventions in our analysis below.

\section{Results}

Table 3 presents estimates of (1), which pertain to the historical polygamy-child mortality relationship. Unconditional on any controls or fixed effects, column (1) shows that children in polygamist households experience on average a 4.3 percentage point higher rate of child mortality, though this is statistically insignificant. In columns (2) through (4), adding fixed effects for town, quarter, and family, reduces this 
Table 3 Polygamy and child mortality: historical data

\begin{tabular}{|c|c|c|c|c|}
\hline & (1) & (2) & (3) & (4) \\
\hline Panel A. Polygamy indicators & \multicolumn{4}{|c|}{ Fraction children dead } \\
\hline \multirow[t]{2}{*}{ Polygynous } & 0.043 & 0.024 & 0.020 & 0.024 \\
\hline & $(0.027)$ & $(0.027)$ & $(0.027)$ & $(0.028)$ \\
\hline Observations & 639 & 639 & 639 & 639 \\
\hline$R^{2}$-squared & 0.003 & 0.025 & 0.067 & 0.153 \\
\hline Fixed effects & None & Town & Quarter & Family \\
\hline AET & & 1.277 & 0.887 & 1.258 \\
\hline Delta & & 0.0333 & 0.0643 & 0.228 \\
\hline Panel B. Wife counts & \multicolumn{4}{|c|}{ Fraction children dead } \\
\hline \multirow[t]{2}{*}{0 wives } & $0.133 * *$ & $0.142 * * *$ & $0.154 * * *$ & $0.132 * *$ \\
\hline & $(0.054)$ & $(0.054)$ & $(0.053)$ & $(0.054)$ \\
\hline \multirow[t]{2}{*}{2 wives } & 0.046 & 0.040 & 0.037 & 0.051 \\
\hline & $(0.033)$ & $(0.033)$ & $(0.031)$ & $(0.032)$ \\
\hline \multirow[t]{2}{*}{3 wives } & 0.055 & 0.016 & 0.003 & -0.015 \\
\hline & $(0.051)$ & $(0.044)$ & $(0.045)$ & $(0.042)$ \\
\hline \multirow[t]{2}{*}{$4+$ wives } & $0.100^{*}$ & 0.047 & 0.051 & 0.020 \\
\hline & $(0.055)$ & $(0.053)$ & $(0.055)$ & $(0.059)$ \\
\hline Observations & 639 & 639 & 639 & 639 \\
\hline$R^{2}$ & 0.017 & 0.040 & 0.084 & 0.166 \\
\hline Fixed effects & None & Town & Quarter & Family \\
\hline
\end{tabular}

Notes: Robust standard errors in parentheses. All regressions are OLS and include a constant (not reported) $* * *$ Significant at $1 \%, * *$ Significant at $5 \%, *$ Significant at $10 \%$

estimate by nearly half. The corresponding Altonji et al. (2005) ratios, which range from 0.887 to 1.277 , reflect this reduction in coefficient magnitude. Oster (2016) $\delta$ statistics are much lower, ranging from 0.03 to 0.23 . This reflects the fact that, even where the estimate of $\beta$ has been relatively stable, the increase in the $R^{2}$ from the added fixed effects is small; that is, the fixed effects reduce the size of the coefficient by a large amount relative to how little of the remaining variance they explain.

The bottom half of the table provides estimates of (1) using categorical measures of polygamy. In columns (1) through (4), it is apparent that households in which the head has no living wives generally have elevated levels of child mortality relative to those of monogamists. Although polygamists have higher levels of child mortality than monogamists, these coefficients are generally statistically insignificant. Altonji et al. (2005) ratios and $\delta$ statistics for these specifications are not reported here, since there are now multiple coefficients of interest.

In sum, the baseline correlation of polygamy with child mortality in the historic data is consistently positive, but statistically insignificant. The sensitivity of the estimates to additional fixed effects that do not themselves explain much of the remaining variance is consistent with an important role for selection on unobservables. The weakness of the correlation that exists in the historic data is suggestive that the correlation in the present may derive in part from forms of selection that 
divide households into those that are more "traditional" and those that are more "modern," based, for example, on beliefs or attitudes, or on access to information, health services, or the modern economy. Indeed, the results we will present regarding mechanisms such as behavioral practices and selection into polygamy accord with this explanation. However, this finding should be interpreted cautiously, since the correlation is positive, and statistical insignificance may also be due to issues of statistical power. Nevertheless, the sensitivity to quarter and family fixed effects suggests an important role for unobserved heterogeneity of a type not captured in many studies that use modern data.

Table 4 presents estimates of (2), which pertain to the polygamy-child mortality relationship in the present day. The unconditional association in column (1) suggests that children are 8 percentage points more likely to die in the first five years of life if they have a polygamist mother. The fraction of the variance explained, however, is negligible. The addition of baseline controls reduces the estimate to 4.5 percentage points in column (2), without adding much explanatory power. Similarly, adding fixed effects for survey clusters in column (3) reduces the estimate to 3.9 percentage points, but adds little to the $R^{2}$. Adding both sets of controls in column (4) reduces the coefficient size further still, to 3.3 percentage points. Altonji et al. (2005) ratios

Table 4 Polygamy and child mortality: modern data

(1)

Child died in first 5 years

Panel A. Polygamy indicators

Polygynous

Observations

$R^{2}$

Fixed effects

Controls

AET

Delta

Panel B. Wife counts

2 wives

3 wives

4+ wives

$R^{2}$

Fixed effects

Controls

$0.080 *$
$(0.016)$
11,295
0.007
None
No

(0.016)

, 295

None

0.0508

Child died in first 5 years

$0.072 * * *$

(0.017)

$0.118 * * *$

0.079

(0.049)

11,295

0.008

None

No
(0.029)
(2)

$0.045 * * *$

(0.014)

11,288

0.035

None

Yes

1.309

0.040 **

(0.016)

$0.072 * *$

(0.030)

0.045

(0.039)

11,288

0.035

None

Yes
(3)

(4)

$0.033 * *$

(0.016)

11,288

0.066

Cluster

Yes

0.694

0.0511

0.0561

0.027

(0.017)

0.054

(0.034)

0.043

(0.039)

11,288

0.066

Cluster

Yes

Notes: Standard errors clustered by PSU in parentheses. All regressions are OLS and include a constant (not reported). Controls are multiple birth, female, year of birth, mother age and its square, head's age and its square, mother's education, and wealth index

$* * *$ Significant at $1 \%, * *$ Significant at $5 \%, *$ Significant at $10 \%$ 
and $\delta$ statistics for columns (3) and (4) are both smaller than one, again suggesting a large role for selection on unobservables in explaining the relationship between polygamy and early childhood mortality. The bottom panel of the table shows a similar pattern when using categorical measures of polygamy.

The correlations of polygamy conditional on controls in the historic data $(2.4$ percentage points) and in the modern data (3.3 percentage points) can be put in context by comparing them to other recent work on the sources of infant mortality in both economic history and development economics. These are magnitudes comparable to those produced by the decline of coal in heating in the United States (3.27 percentage points in Barreca et al. 2016), democratization in Africa (1.8 percentage points in Kudamatsu et al. (2012)), a six-month malaria epidemic in Africa (3.5 percentage points in Kudamatsu (2012)), a one standard deviation rise in hightemperature days in India $(7.3 \%$ in Burgess et al. (2014)) or aggregate income fluctuations in India (an elasticity of -0.33 in Bhalotra (2010)). These correlations, whatever their source, are clearly of economically meaningful and policy-relevant magnitudes.

\section{Mechanisms}

The main results above already suggest that selection into polygamous household forms may play an important role in explaining both the past and present correlations of polygamy with child mortality. In this section, we test the sensitivity of our estimates of $\beta$ and $\theta$ to additional controls and use these results to make inferences about the possible channels that best account for the relationship.

\subsection{Resource dilution}

We begin in Table 5 by considering whether measures of resource dilution help explain the historical correlation of polygamy with child mortality. We consider three measures of the resource pressure put on any one wife by polygamy: the total number of births reported, the number of children per wife (living or dead), and the number of children per living wife. ${ }^{10}$ Each of these indicators is positively correlated with the fraction of children in the household who have died. This may be because they are indeed indicators of resource pressure (e.g., Gage 1997; Sellen 1999); however, this finding may also result from parents responding to the death of a child by increasing their fertility, or may be driven by other unobserved variables.

What is clear from the table, however, is that-relative to column (1) of Table 3these resource pressure measures do little to the coefficient estimate on polygamy. Altonji et al. (2005) ratios are negative, since the estimate of $\beta$ increases with the inclusion of these controls. This suggests that the pressure of additional children per wife is unlikely to explain the raw correlation between polygamy and child mortality in the data. Oster (2016) $\delta$ statistics, however, suggest a more cautious interpretation:

\footnotetext{
${ }^{10}$ It is worth noting, as will be discussed in the following section, that while these measures may capture resource dilution, they may also capture physical overcrowding in polygamist households. In the absence of data on housing arrangements, it is impossible to isolate the two.
} 
Table 5 Mediation: historical data

(1)

Fraction of children dead

Panel A. Resource dilution

Polygynous

Children (living+dead)

Children per wife

Children per living wife

$-0.045$

(0.031)

$0.017 * * *$

(0.003)

$0.014 * * *$

(0.006)

Observations

$R^{2}$

AET

Delta

Panel B. Crowding and intra-household allocation

Polygynous

Observations

$R^{2}$

Controls

Fixed effects

AET

Delta

Fraction of children dead
$0.052 *$

(0.028)

(2)

(3)

$0.082 * * *$

(0.027)

$\begin{array}{lll} & 0.014 * * * & \\ & (0.006) & \\ & & 0.027^{* * *} \\ & & (0.004) \\ 639 & 639 & 587 \\ 0.057 & 0.013 & 0.080 \\ -0.515 & -5.627 & -2.072 \\ -0.0204 & -0.0296 & -0.106\end{array}$

$\begin{array}{lll}0.124 * * * & 0.067 * & 0.070 * * \\ (0.034) & (0.036) & (0.029) \\ 639 & 639 & 638 \\ 0.151 & 0.127 & 0.232 \\ \text { None } & \text { Composition } & \text { Shares } \\ \text { HH Size } & \text { None } & \text { None } \\ -1.527 & -2.771 & -2.579 \\ -0.126 & -0.328 & -0.666\end{array}$

Notes: Robust standard errors in parentheses. All regressions are OLS and include a constant (not reported) $* * *$ Significant at $1 \%, * *$ Significant at $5 \%, *$ Significant at $10 \%$

these are generally very low in absolute value, reflecting the fact that the additional controls explain little of the unexplained variance. Relative to this modest increase in $R^{2}$, the estimates of $\beta$ are unstable. The $\delta$ statistics are, however, negative: selection on unobservables would need an opposite sign to selection on observables to explain the result. The exception here is column (1), in which controlling for the total number of children leads the coefficient on polygamy as defined by living wives to flip sign.

Table 6 reports the results of a similar exercise with the modern sample, though the detail in the DHS data allow us to more precisely capture the resource pressure on the specific child in the sample. In particular, we use birth order, a dummy for a multiple birth, and the time since the mother's last child-variables which we can only compute for higher-order births. All of these controls either raise the estimate of $\theta$ relative to column (1) of Table 4, or change it only slightly. The Altonji et al. (2005) ratios, as a result, are either large or negative. The Oster (2016) $\delta$ statistics are also largely negative, though they are again very small, suggesting that these measures of resource pressure do little to explain the additional variance. Together, and in accordance with studies such as Desai (1992) and Strassmann (1997), these results 
Table 6 Mediation: modern data

(1)

Child died in first 5 years

Panel A. Resource dilution

Polygynous

Birth order number

$0.075 * *$
$(0.015)$
$0.009 * *$

(0.002)

Child multiple

Preceding birth interval (months)

Junior wife

Fixed effects

Observations

$R^{2}$

AET

Delta

(3)

(4)

(5)

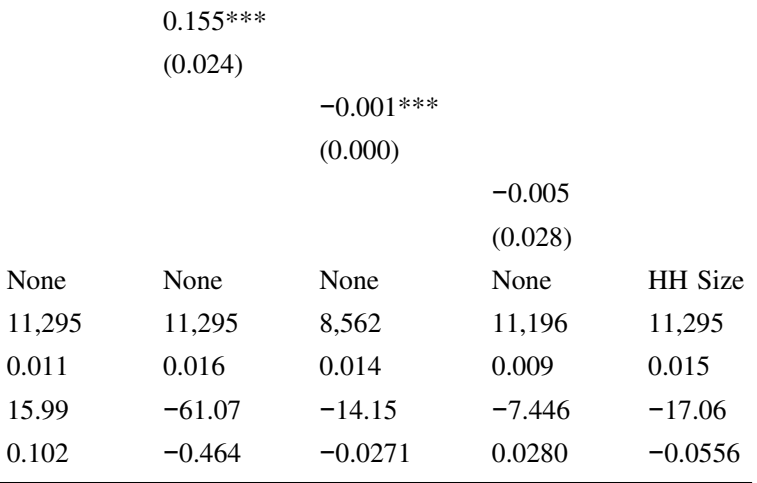

Notes: ***Significant at $1 \%, * *$ Significant at $5 \%, *$ Significant at $10 \%$. Standard errors clustered by PSU in parentheses. All regressions are OLS and include a constant (not reported)

suggest resource dilution is unlikely to account for the link between polygamy and child mortality in either sample, and that measures of resource pressure do not themselves explain much of the variation in mortality.

For both the modern and historical samples, we interact polygamy with our measures of resource pressure in the appendix, in Table 11. This provides some suggestive evidence that resource pressures are worse in polygamous households in the modern sample, but there is no evidence of this in the historical sample. In the appendix, in Table 12, we also report these results controlling for the fraction of the household consisting of children under five years old.

\subsection{Crowding}

It is difficult to disentangle crowding and resource pressure in the data that we have. Given this constraint, in Tables 5 and 6, we report results controlling for a vector of household-size fixed effects. These may better capture crowding than the measures of the number of children used above, since they are not child-specific. In both tables, controlling flexibly for the number of individuals in the household in this manner increases the estimate of $\beta$ or $\theta$, leading to negative Altonji et al. (2005) ratios and Oster (2016) $\delta$ statistics, although the latter remain small, since controlling for household size does little to explain the additional variance. As with resource dilution, these results provide little evidence that physical overcrowding of the like found by Aaby et al. (1983b) and Garenne and Aaby (1990), and the concomitantly higher 
risk of disease transmission, can explain the correlation between polygamy and child mortality.

In appendix Table 13, we add additional measures of crowding-the number of rooms for sleeping, whether the household shares a toilet with other households, and the number of total rooms. We consider these either controlling for the number of children and household size, or per capita, or per child. As with Table 6, the results suggest that crowding-related resource pressure is positively correlated with mortality, that controlling for such proxies does little to reduce $\theta$, but that $\theta$ is sensitive to these controls relative to the additional explained variance.

\subsection{Intra-household allocation}

We take three approaches to assessing whether tension in intra-household resource allocation, of the like identified by Brahmbhatt et al. (2002), is a likely channel for the correlation between polygamy and child mortality. The first proceeds in the spirit of Deaton (1989), who examines the role of household gender and age composition on consumption. In this approach, we assess whether the correlation of polygamy and child mortality differs by child gender. If polygamy reduces the bargaining power of women or changes the relative value of sons vs. daughters (e.g., Doepke et al. 2012; Tertilt 2005), we might expect to find a sex bias in child survival that is not present in monogamous households. In Table 7 , we report results for both historic and modern data. The historic data are suggestive of a differential correlation with polygamy by gender; the estimate of $\beta$ is larger for daughters. The modern data do not yield the same conclusion. Although estimating the results separately for boys and girls gives a coefficient estimate that is larger for girls, when pooling the sample together, the correlation of polygamy with child mortality is not statistically significantly larger for girls. Indeed, the interaction is negative in this pooled sample.

Our second approach is to look for differential outcomes for the children of junior wives. This is only possible in the modern data, and the results are reported in column (4) of Table 6. We code "junior wife" as a dummy equal to zero if the child's mother is either the senior wife or is a monogamist, and one if she is a polygamist who is not the senior wife. So, this regression asks whether the correlation of polygamy with child mortality is more severe for junior wives than the positive correlation already arising from membership in a polygamist household. The results, which stand in contrast to those in Kazianga and Klonner (2006), suggest that this is not the case: the coefficient on the junior wife dummy is negative and statistically insignificant. Meanwhile, the Altonji et al. (2005) ratio is large and negative, reflecting an increase in $\theta$, and the Oster (2016) $\delta$ statistic is similarly negative. Together, these statistics imply that selection on observable characteristics would need a sign opposite to selection on unobservables to explain away the relationship captured by $\theta$. However, the $\delta$ is also small; the junior wife dummy does little to explain the total variation in child mortality.

Finally, in Table 5 we control for the age and gender composition of the households in our historical data by including a set of controls that capture the number of individuals in each age-gender bin. This similarly follows the spirit of Deaton (1989). Controlling for these dummies makes the estimated correlations between polygamy and child mortality larger, and indeed leads to the largest estimates of $\delta$ that we 
Table 7 Polygamy and child mortality: by gender

\begin{tabular}{|c|c|c|c|}
\hline & $\begin{array}{l}\text { (1) } \\
\text { Fraction } \\
\text { sons dead }\end{array}$ & $\begin{array}{l}(2) \\
\text { Fraction } \\
\text { daughters } \\
\text { dead }\end{array}$ & (3) \\
\hline \multicolumn{4}{|l|}{ Panel A. Historic data } \\
\hline Polygynous & $\begin{array}{l}0.025 \\
(0.033)\end{array}$ & $\begin{array}{l}0.071 * * \\
(0.032)\end{array}$ & \\
\hline Observations & 555 & 564 & \\
\hline$R^{2}$ & 0.001 & 0.007 & \\
\hline Panel B. Modern data & \multicolumn{3}{|c|}{ Child died in first 5 years } \\
\hline Polygynous & $\begin{array}{l}0.073 * * * \\
(0.018)\end{array}$ & $\begin{array}{l}0.086 * * * \\
(0.022)\end{array}$ & $\begin{array}{l}0.086 * * * \\
(0.022)\end{array}$ \\
\hline Polygamous $\times$ Female & & & $\begin{array}{l}-0.013 \\
(0.024)\end{array}$ \\
\hline Child female & & & $\begin{array}{l}-0.023^{* * *} \\
(0.006)\end{array}$ \\
\hline Observations & 5,436 & 5,859 & 11,295 \\
\hline$R^{2}$ & 0.007 & 0.008 & 0.009 \\
\hline Sample & Girls & Boys & All \\
\hline
\end{tabular}

Notes: Robust standard errors in parentheses for historical data; standard errors for modern data are clustered by PSU. All regressions are OLS and include a constant (not reported)

$* * *$ Significant at $1 \%, * *$ Significant at $5 \%, *$ Significant at $10 \%$

report. Results are similar if we replace these counts with the bin's share of the total household. These household composition measures are unlikely to drive the correlation of polygamy with child mortality, and suggest that household composition is unlikely to serve as a mediator or confounder that explains the relationship between polygamy and child mortality.

\subsection{Behavioral practices}

In order to assess whether behavioral practices towards children differ between polygamous and non-polygamous households, we test for correlations between polygamy and parental investments in the DHS children's recodes, and report results in Table 8. This is the subset of children born in the five years before the survey, and so is smaller than our baseline sample. Although these data contain more detail on children's early-life treatment, they preclude our looking at investments in later childhood, such as schooling. At first glance, it appears that the children of polygamous mothers receive far fewer investments than their monogamist counterparts. Negative correlations with polygamy are apparent for several measures of prenatal and birth-related care, as well as for vaccinations. These results are consistent with behavioral explanations (themselves potentially a function of the selection of poorly educated, rural, or culturally conservative individuals into polygamy) such as those proposed by Amankwaa (1996) and Stephenson et al. (2006); as well as with the 


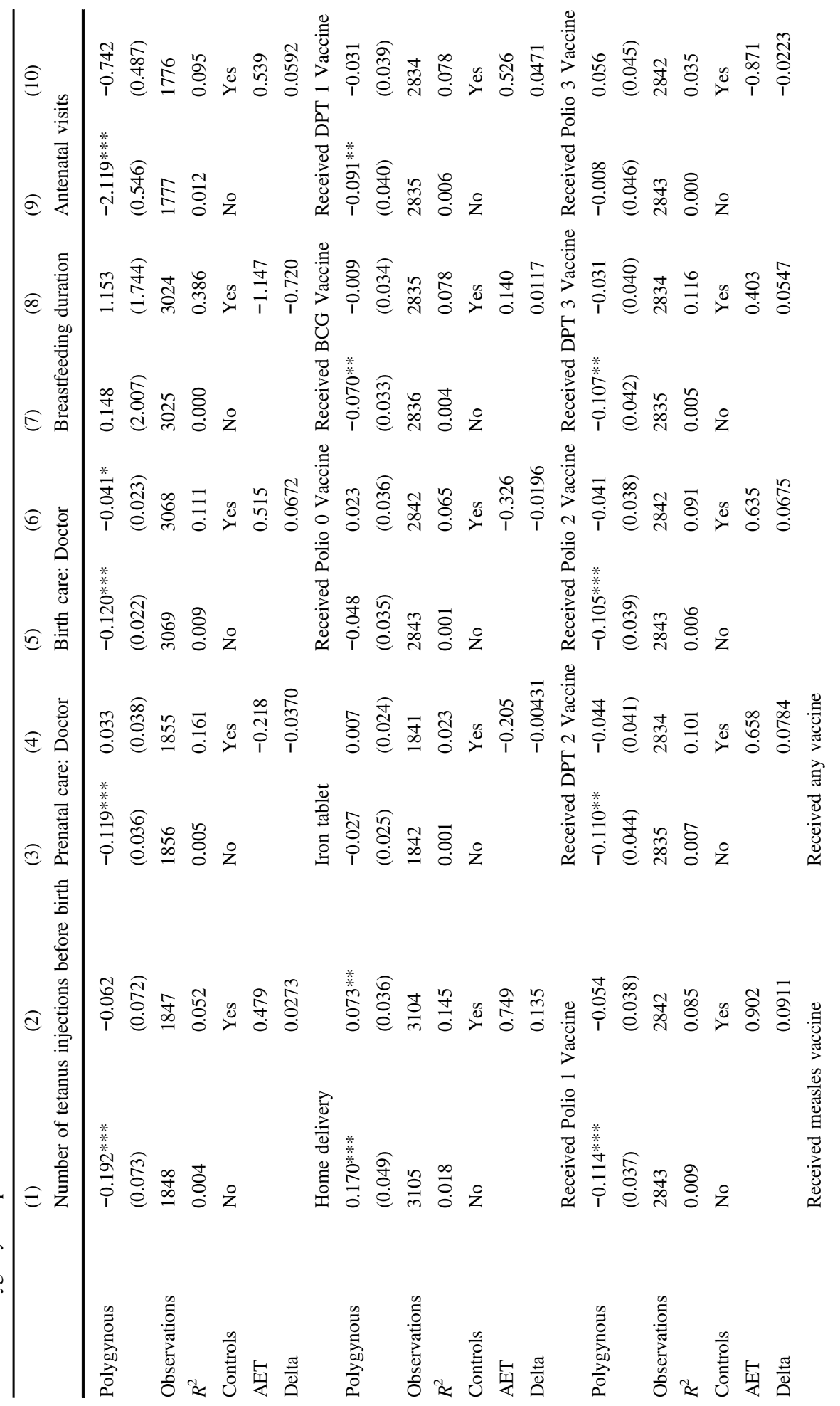




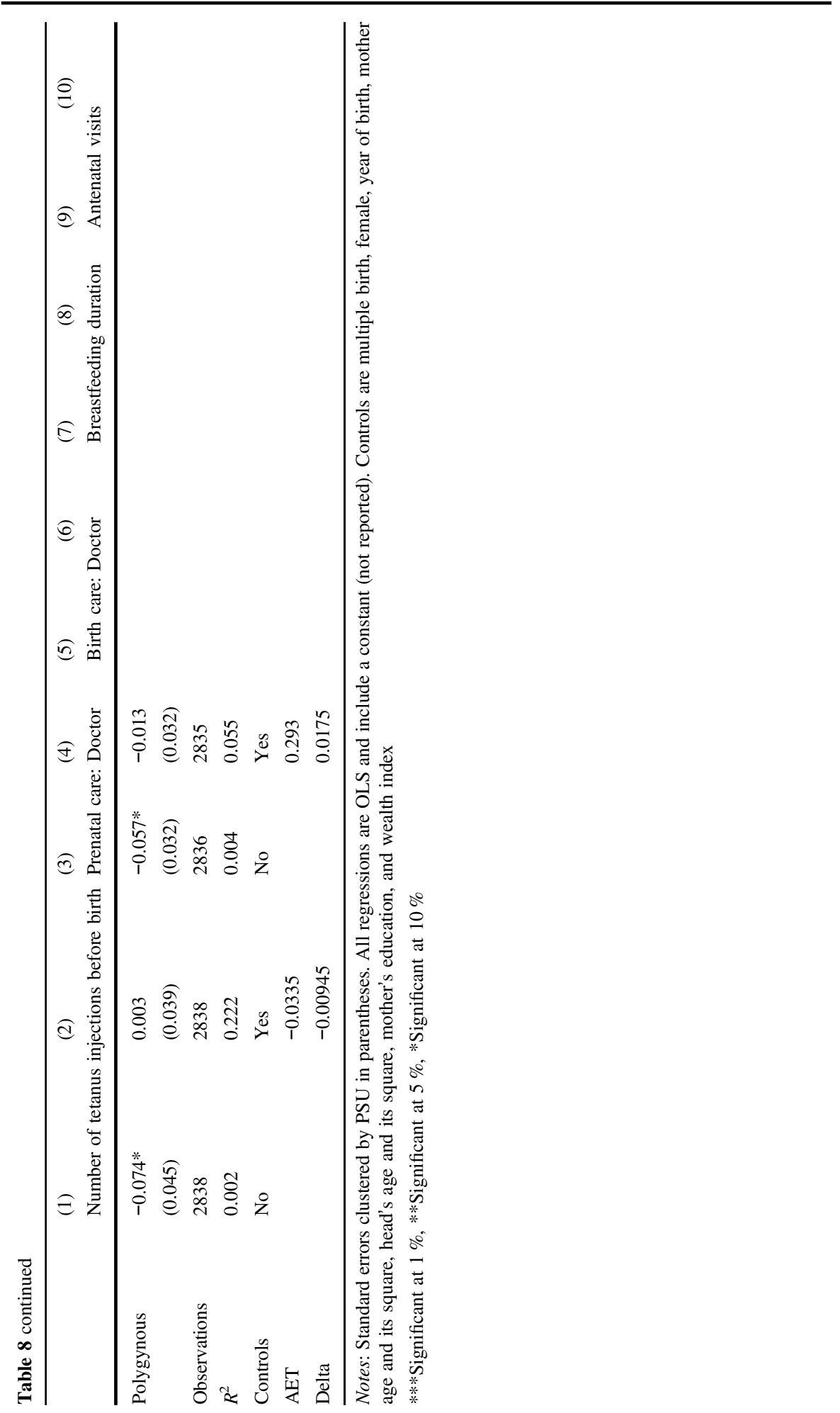


resource pressure explanations outlined by Desai (1992) and Gage (1997), who cite the dilution of a polygamist father's healthcare budget as a potential driver of poor early-life health investments in his children. Unsurprisingly, there is a positive and statistically insignificant correlation with breastfeeding duration, given the postpartum sex taboos that are particularly strong in more traditional households. However, including the baseline set of controls from Table 3 leads most of these correlations to become statistically insignificant or to fall substantially in magnitude.

In appendix Table 14, we show that controlling for maternal education and the DHS wealth index is sufficient to make many of these correlations statistically insignificant, suggesting that the failure of polygamous mothers to invest in earlychildhood medical care may reflect selection into polygamy more so than it reflects a polygamist-specific cultural practice. Altonji et al. (2005) ratios and Oster (2016) $\delta$ statistics are both small across several outcomes, suggesting again that unobserved correlates of polygamy, such as skepticism of modern medical practices or poor access to health facilities, are likely to play a substantial role in explaining the unconditional correlations.

\subsection{Selection}

The Altonji et al. (2005) ratios and Oster (2016) $\delta$ statistics reported in Tables 3 and 4 are already suggestive of an important role for selection in explaining the correlation between polygamy and child mortality. In Table 9, we report (i) the correlation of several predetermined maternal and parental characteristics with polygamy, and (ii) the degree to which these characteristics influence the correlation of polygamy and child mortality. In the modern data, children of polygamists are more likely to be born to mothers who are illiterate, older, less educated, married earlier, urban, poor, in households with an older head, and whose partners are less likely to have completed primary school. Many of these correlations are similar to those in other studies which point to the importance of polygamist selectivity by observable characteristics in driving these households' child mortality "penalty" (e.g., Amankwaa 1996; Omariba and Boyle 2007; Smith-Greenway and Trinitapoli 2014), though the positive correlation with urban and the lower values of the wealth index stand out as particular to the context of the relatively urban and wealthy Igbo sample. These findings also suggest that polygamy is more likely to be prevalent in poor or rural communities which might suffer from other contributors to child mortality, such as poor access to public health services or norms of gender inequality.

Across columns, these observable parental characteristics do little to reduce the correlation of polygamy with child mortality: Altonji et al. (2005) ratios are largely greater than one or are negative; estimates of $\theta$ either increase or decline slightly. Estimates of $\delta$, as before, are small. These additional covariates move $\theta$ a substantial amount relative to the marginal increases in $R^{2}$ achieved by including them. The two variables that do the most to reduce $\theta$ here are the education of the mother and the wealth index. These findings are suggestive of a potentially important role for selection on unobservable characteristics that are similar to the observables included here.

In sum, the sensitivity of the correlations of polygamy with child mortality in both the modern and historical data are indicative of an important role for selection on 


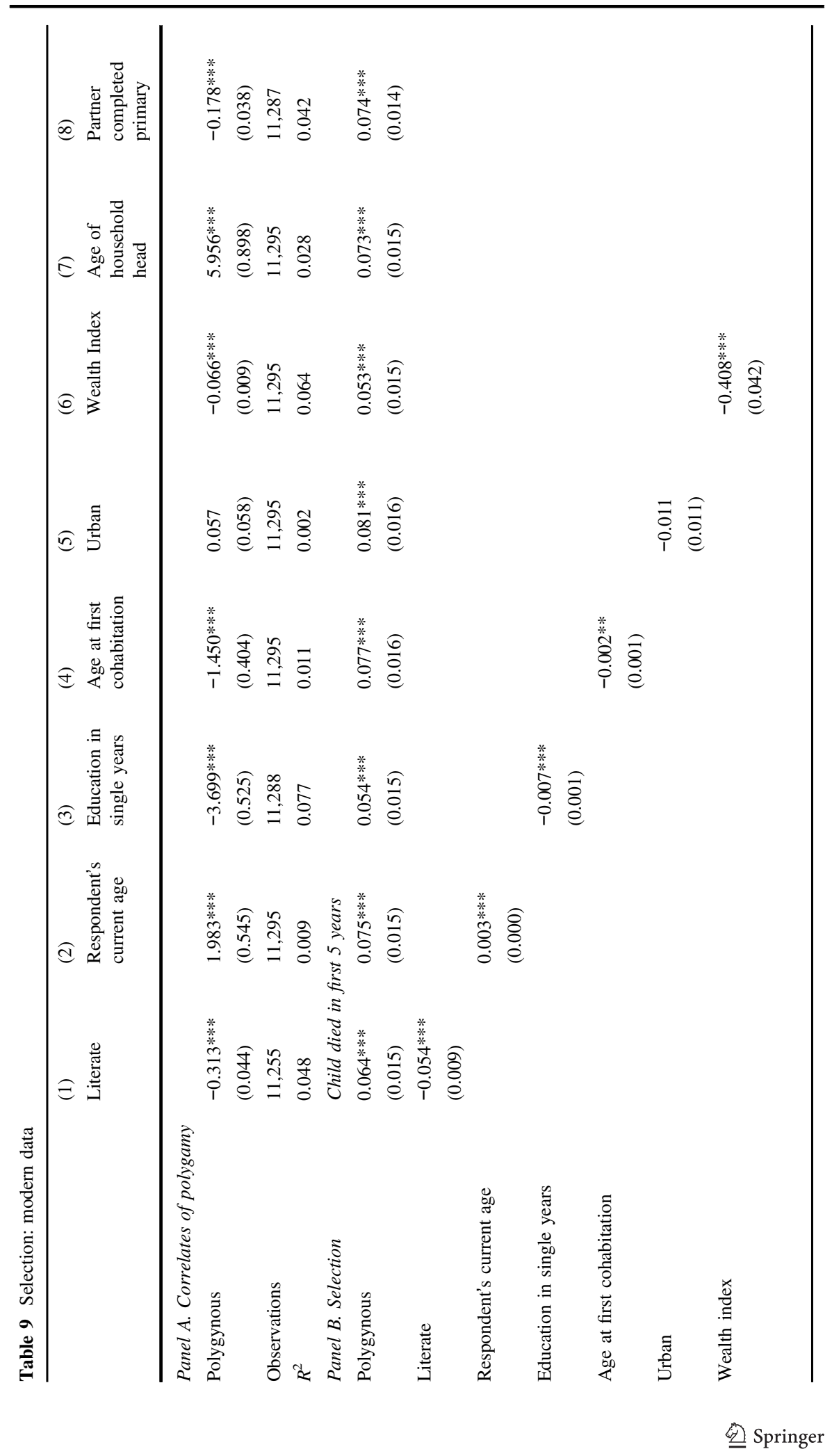




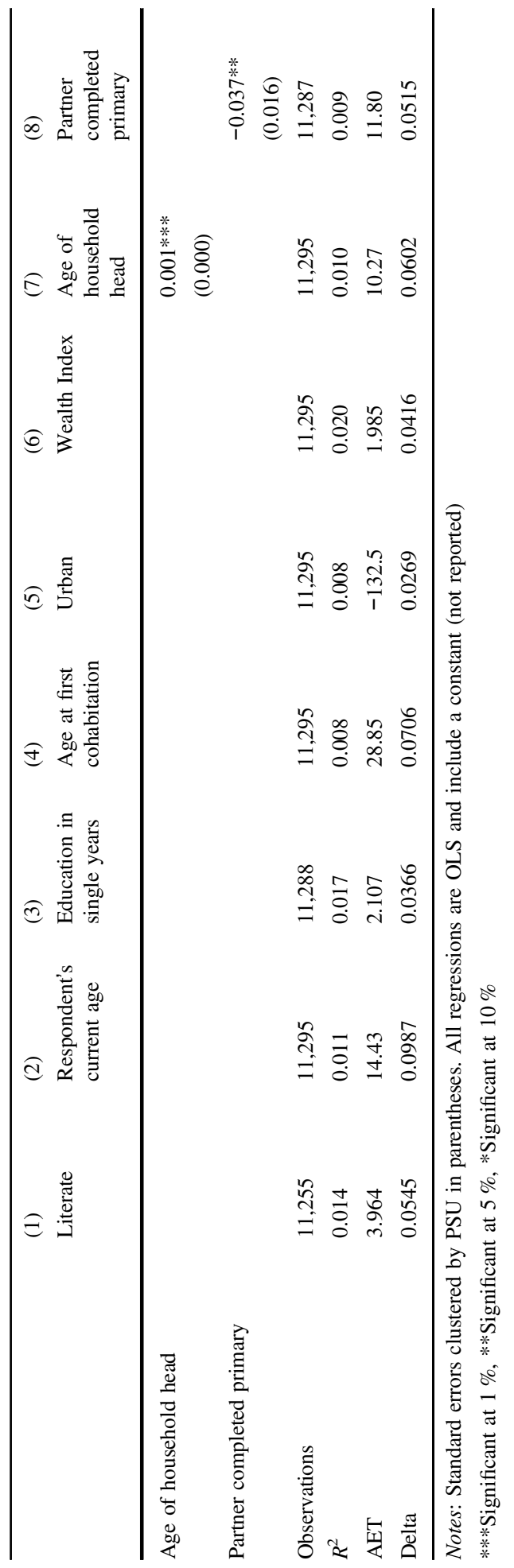


unobservables in explaining the relationship. We consider the sensitivity of $\beta$ and $\theta$ to observables related to the hypotheses of resource dilution, crowding, intrahousehold allocation and behavioral practices, as well as to observable markers of selection. Frequently, these make our estimates of $\beta$ or $\theta$ larger, suggesting that they do not capture dimensions of selection that, once fully controlled for, would push $\beta$ or $\theta$ toward zero. Rather, the general sensitivity of $\beta$ or $\theta$ to controls that do little to increase the total $R^{2}$ is indicative of selection into polygamy along dimensions not captured here.

What, then, might explain the correlation between polygamy and child mortality? Observable characteristics that do substantially reduce $\beta$ or $\theta$ include the vectors of location fixed effects, total children (in a single historical specification), maternal education, and wealth. These suggest that the most promising candidates for margins of selection are unobserved features of the opportunities available to women, of socioeconomic status, and of places that are more likely to be home to polygamists.

\section{Conclusion}

In this paper, we have shown that the children of polygamists suffer a mortality "penalty" in both historical and modern Igboland, though this is only statistically significant in the present. These results suggest that a net adverse association exists between polygamy and child survival in this context, despite any potentially beneficial characteristics of polygamous households, such as higher levels of household wealth, longer durations of breastfeeding, or the potential for co-wife cooperation.

Tests of the mechanisms which may drive the association between polygamy and child mortality suggest that the raw correlations we find may largely be a function of selection into polygamy-particularly by unobserved characteristics of individuals, households, and regions. Indeed, few of the channels identified in the larger literature on polygamy and health appear to be at play in our data. For instance, measures of simple resource pressure and of disease transmission risk via physical overcrowding, although themselves statistically significant, do not substantially explain the correlation between polygamy and child mortality. Similarly, although we find limited evidence of gender discrimination in our data, any junior-wife deficits in intrahousehold bargaining power do not appear to manifest in their children's mortality outcomes.

Those of our findings which do help explain the relationship between polygamy and poor child survival suggest polygamist selectivity based both on observable characteristics and behaviors (e.g., poverty, poor maternal education, failure to seek adequate prenatal and early-life medical care) and on similar unobservable characteristics of the individuals practicing polygamy and the regions in which polygamy is prevalent. The Altonji et al. (2005) ratios and Oster (2016) $\delta$ statistics reported throughout, too, suggest a strong role for unobservables in driving polygamistspecific behaviors, and the polygamy-child mortality correlation more generally found in our data.

In contrast to a literature which tends to emphasize specific features of polygamy as leading to heightened mortality, our findings suggest that the correlation between polygamy and child mortality may arise largely from the selection of poor, poorly- 
educated individuals-especially women-into polygamous unions. In turn, the characteristics of polygamist mothers that we observe may correlate with unobservable ones, such as poor marriage options or culturally conservative attitudes, that too result in poor child survival. A key implication of our results is that although membership in polygamous households may be an easy way to identify at-risk children, polygamy as a marital institution is unlikely to cause child mortality in our setting. These findings tend to suggest that eradicating polygamy may be less important to child health in such contexts than would be reducing poverty and improving women's access to education and public health services more generally. In emphasizing the role of poverty and associated behaviors in producing the polygamy-child mortality correlation in historical and present-day Nigeria, our work accords with Angus Deaton's findings on income gradients in health and on the importance of accounting for selection, be it behavioral or biological, as a confounder in the study of health in poor settings. It also extends his research on the importance of household composition on well-being by considering how household marital form may, through household size and compositional differences, correlate with child health.

Of course, a limitation of our data is that they do not allow us to make definitive claims regarding the causal impact of polygamy on child mortality. Indeed, our key results are consistent with polygamy being endogenous to the same poor socioeconomic conditions that undermine child health in our setting. Accordingly, future research should focus on the determinants of selection into polgyamy, especially for women, since it may be through these margins (e.g., poverty reduction and female education and employment) that child health interventions may be more effectively implemented.

Funding: We are grateful for financial support from the Economic Growth Center at Yale University, and to Benuel Ganesan for data entry.

\section{Compliance with ethical standards}

Conflict of interest The authors declare that they have no competing interests.

Open Access This article is distributed under the terms of the Creative Commons Attribution 4.0 International License (http://creativecommons.org/licenses/by/4.0/), which permits unrestricted use, distribution, and reproduction in any medium, provided you give appropriate credit to the original author(s) and the source, provide a link to the Creative Commons license, and indicate if changes were made.

\section{Appendix}

\section{Polygamy rates for Sub-Saharan Africa}

Our estimates of polygamy rates come from two calculations. First, the fraction of women in polygamous marriages is estimated as $\sum_{c} p_{c}^{w} s_{c}^{w} . c$ indexes the countries of Sub-Saharan Africa, as listed by the World Development Indicators. $p_{c}^{w}$ is the fraction of women in the most recent Demographic and Health Survey individual recode 
file for country $c$ who report that her husband has more than one wife. $s_{c}^{w}$ is the share of adult women in Sub-Saharan Africa that are in country $c$. The number of adult women in country $c$ is estimated as $\pi_{c}^{w}\left(1-\pi_{c}^{U 14}\right) N_{c}$, where $\pi_{c}^{w}$ is the share of the population of country $c$ that is female, $\pi_{c}^{U 14}$ is the share of the population of country $c$ that is under 14 , and $N_{c}$ is the population of country $c$. These three numbers are all taken from the most recent available year in the World Development Indicators. Second, the fraction of children born to polygamous mothers is estimated as $\sum_{c} p_{c}^{U 14} s_{c}^{U 14} \cdot p_{c}^{U 14}$ is the fraction of living children under 14 in the most recent Demographic and Health Survey births recode file for country $c$ whose mother reports that her husband has more than one wife. $s_{c}^{U 14}$ is the share of children in SubSaharan Africa in country $c$. The number of children in country $c$ is estimated as $\pi_{c}^{U 14} N_{c}$. South Sudan and Sudan are joined together for these calculations. For Angola, $p_{c}^{w}$ and $p_{c}^{U 14}$ are estimated indirectly as the fraction of wives of household heads who are polygamous in the most recent Demographic and Health Survey household recode file. For the Gambia and Mauritania, $p_{c}^{w}$ or $p_{c}^{U 14}$ are not available from the Demographic and Health Survey, and so polygamy rates from Tertilt (2005) are used instead. The calculations exclude Botswana, Cape Verde, Equatorial Guinea, Eritrea, Guinea-Bissau, Mauritius, Seychelles, and Somalia, as their polygamy rates are neither in the Demographic and Health Survey nor in Tertilt (2005). Together, these excluded countries account for less than $3 \%$ of the African population. 


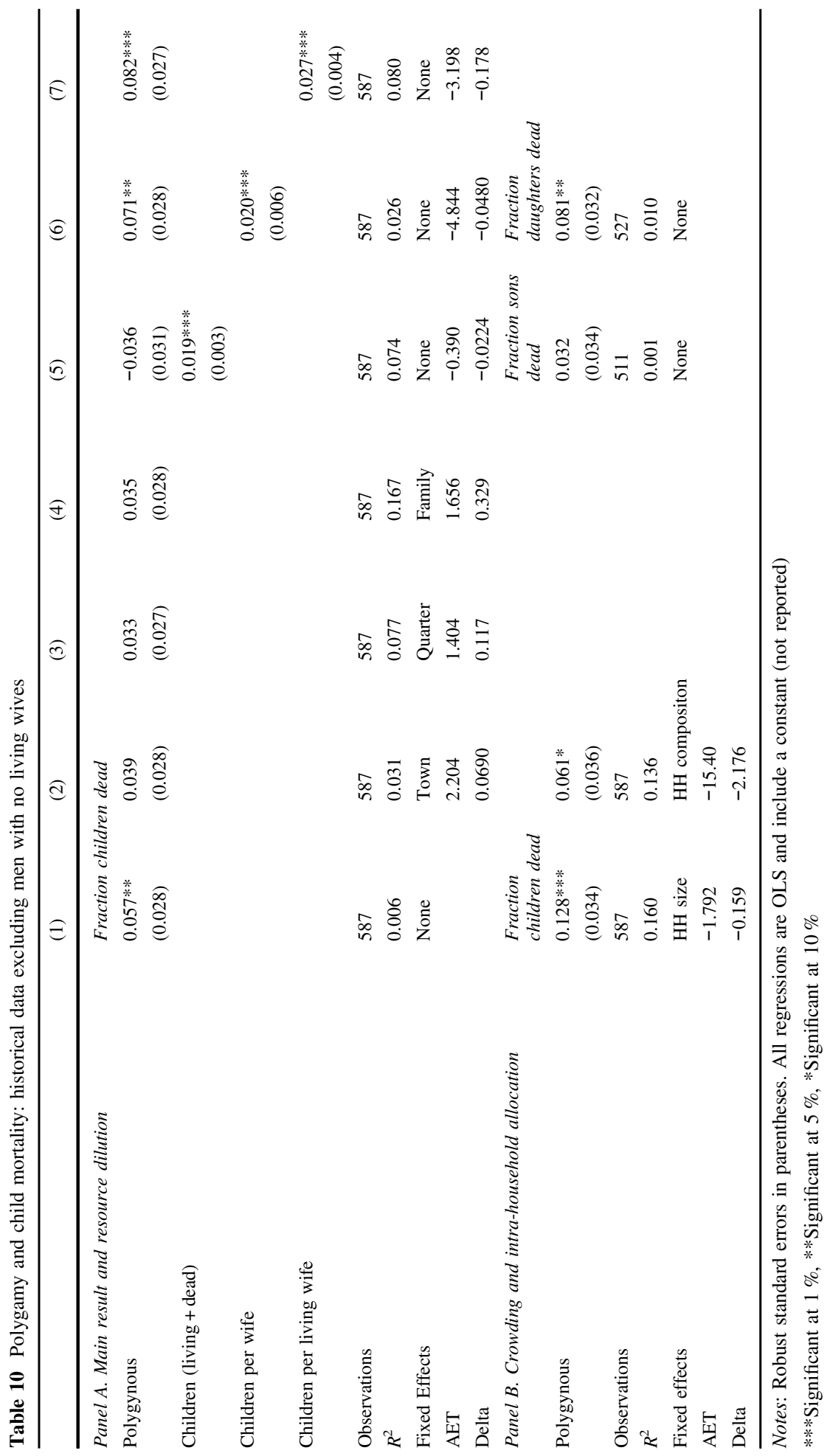


Table 11 Resource dilution with polygamy interactions

(1)

Fraction children dead

Panel A. Historical data

Polygynous

Interaction with polygynous

$\begin{array}{ll}0.029 & 0.011 \\ (0.056) & (0.062) \\ -0.011^{* *} & 0.014 \\ (0.005) & (0.015)\end{array}$

Children per living wife

Children per wife

Children (living + dead $)$

Observations

$R^{2}$

AET

Delta

Panel B. Modern data

Polygynous

Interaction with polygynous

Preceding birth interval (months)

Child multiple

$0.023 * * *$

(0.004)

639

0.062

2.154

0.143

Child died in first 5 years

$\begin{array}{lll}0.043 * & 0.079 * * * & 0.151^{* * *} \\ (0.025) & (0.017) & (0.035) \\ 0.009 & 0.082 & -0.002 * * * \\ (0.006) & (0.080) & (0.001) \\ & & -0.001 * * * \\ & & (0.000)\end{array}$

$0.145^{* * *}$

(0.026)

Birth order number

$0.007 * * *$

(0.002)

11,295

0.011

11,295

8,562

$R^{2}$

1.162

0.017

0.016

AET

0.00867

(3)

$$
\begin{aligned}
& 0.064 \\
& (0.060) \\
& 0.005 \\
& (0.010) \\
& 0.027 * * * \\
& (0.004)
\end{aligned}
$$

$0.013^{* *}$

(0.006)

587

0.080

$-2.954$

$-0.198$

$151^{* * *}$

Delta

Notes: Standard errors clustered by PSU in parentheses. All regressions are OLS and include a constant (not reported)

$* * *$ Significant at $1 \%, * *$ Significant at $5 \%, *$ Significant at $10 \%$ 
Table 12 Mediation: modern data controlling for fraction children
(1)

(2)

(3)

Panel A. Resource Dilution

Child died in first 5 years

Polygynous

$0.075^{* * *} \quad 0.080^{* * *} \quad 0.086^{* * * *}$

$(0.015) \quad(0.016) \quad(0.017)$

Fraction children

$-0.078 * * *-0.091 * * *-0.107 * * *$

$\begin{array}{lll}(0.020) & (0.021) \quad(0.023)\end{array}$

Preceding birth interval

$-0.001 * * *$

(months)

$(0.000)$

Child multiple

$0.154 * * *$

(0.024)

Birth order number

$0.008 * * *$

(0.002)

Observations

$11,295 \quad 11,295 \quad 8,562$

$R^{2}$

$\begin{array}{lll}0.013 & 0.019 & 0.017\end{array}$

AET

$14.34-608.8 \quad-15.93$

Delta

$0.121 \quad-6.633 \quad-0.0871$

Notes: Standard errors clustered by PSU in parentheses. All regressions are OLS and include a constant (not reported)

*** Significant at $1 \%, * *$ Significant at $5 \%,{ }^{*}$ Significant at $10 \%$ 


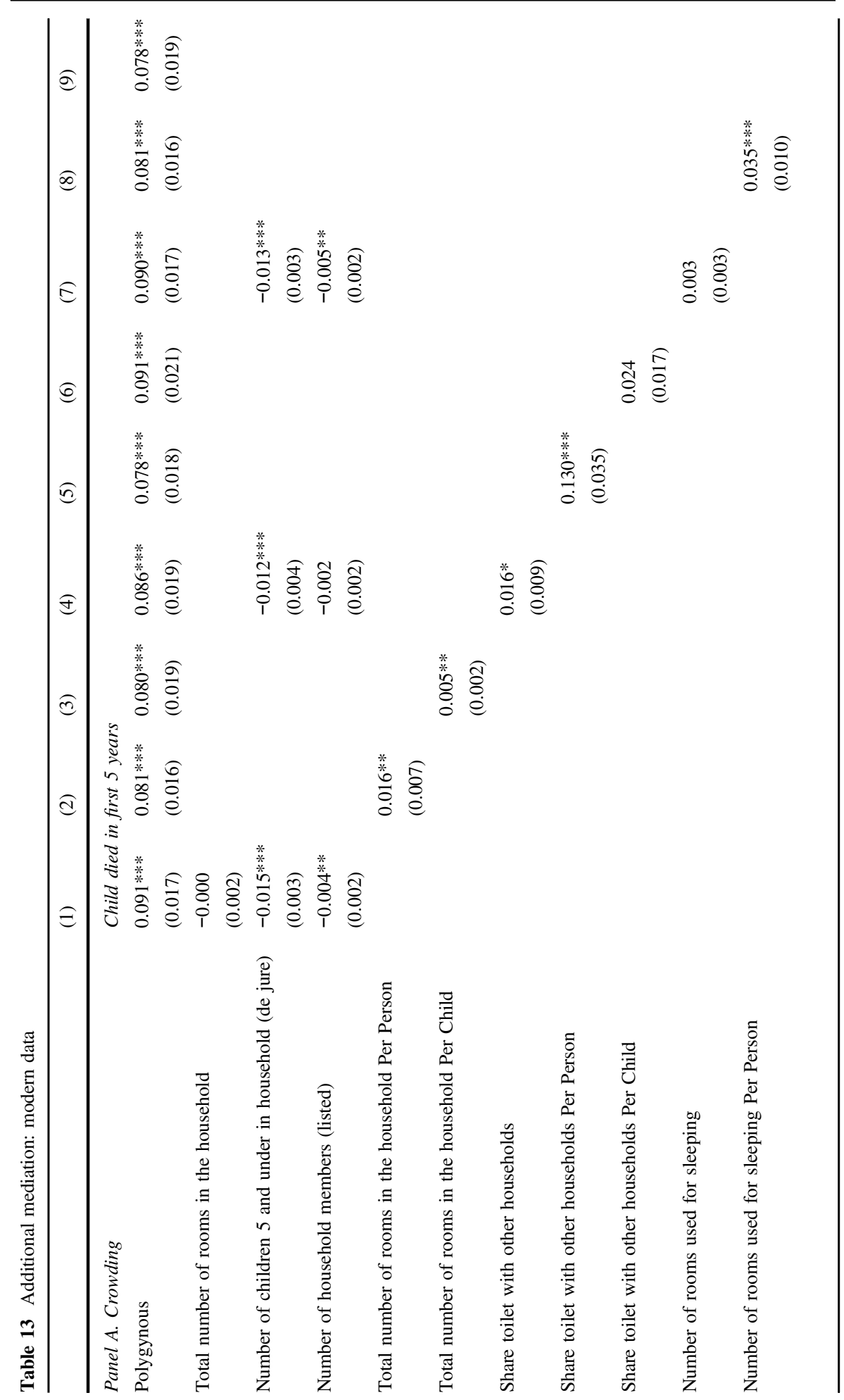




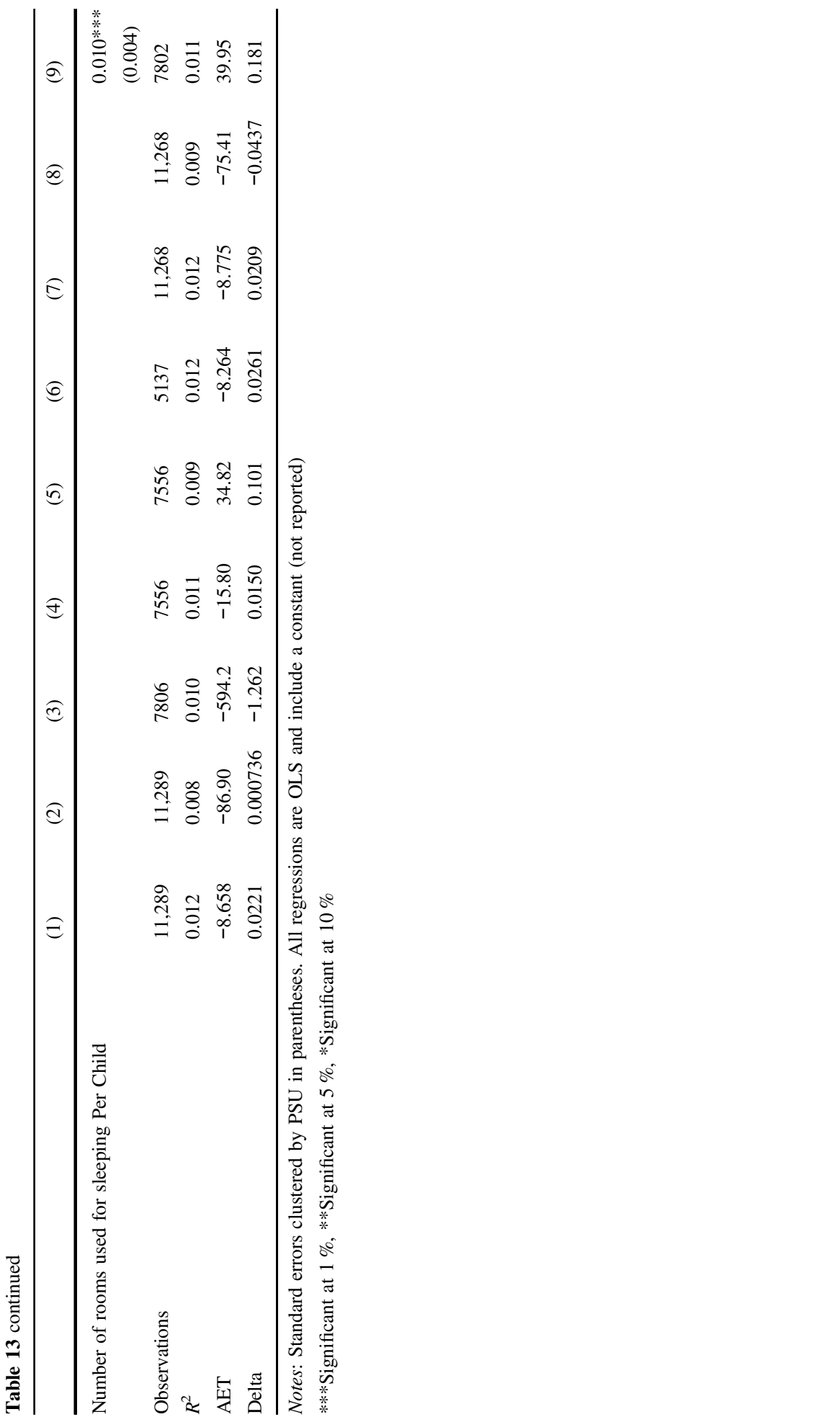




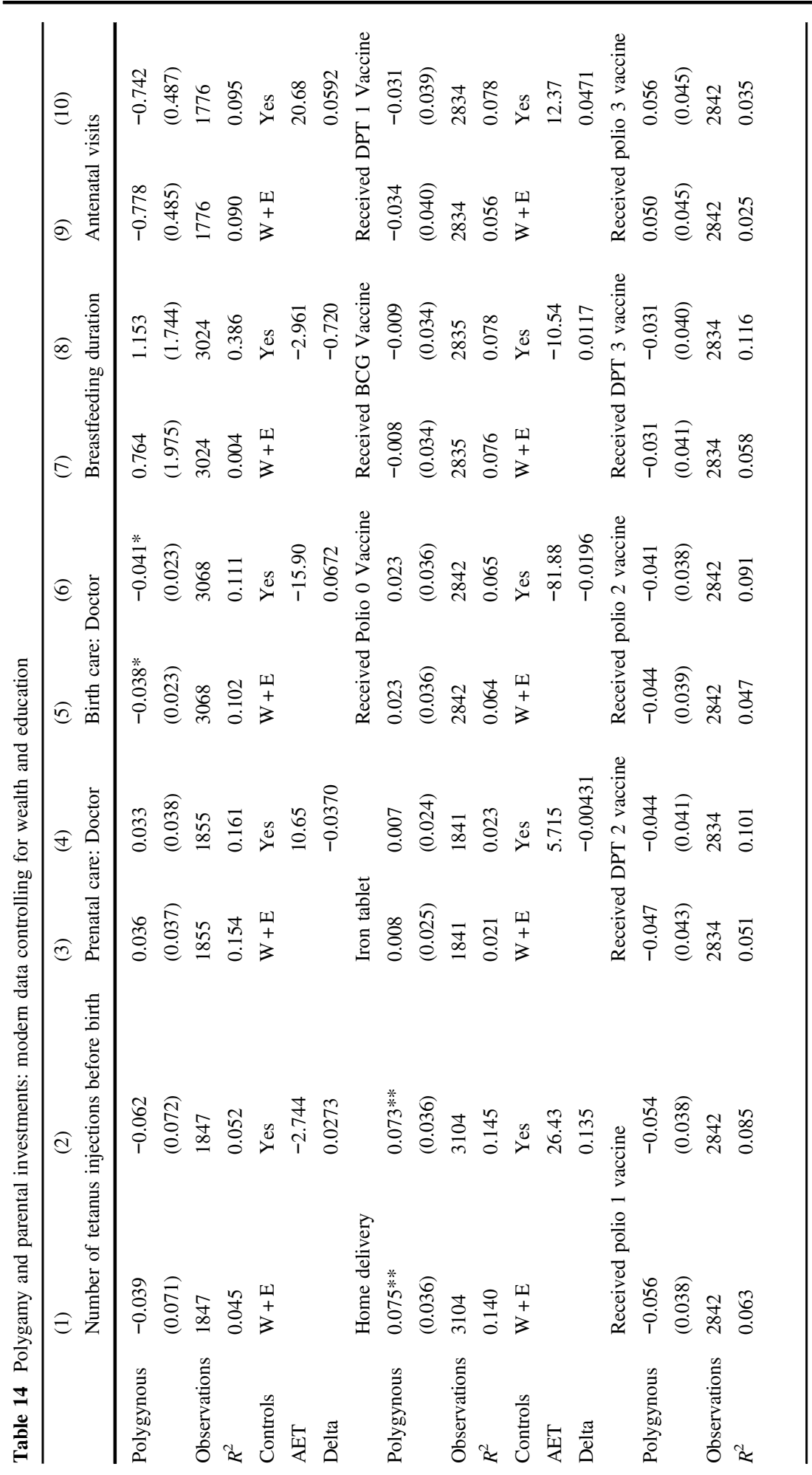




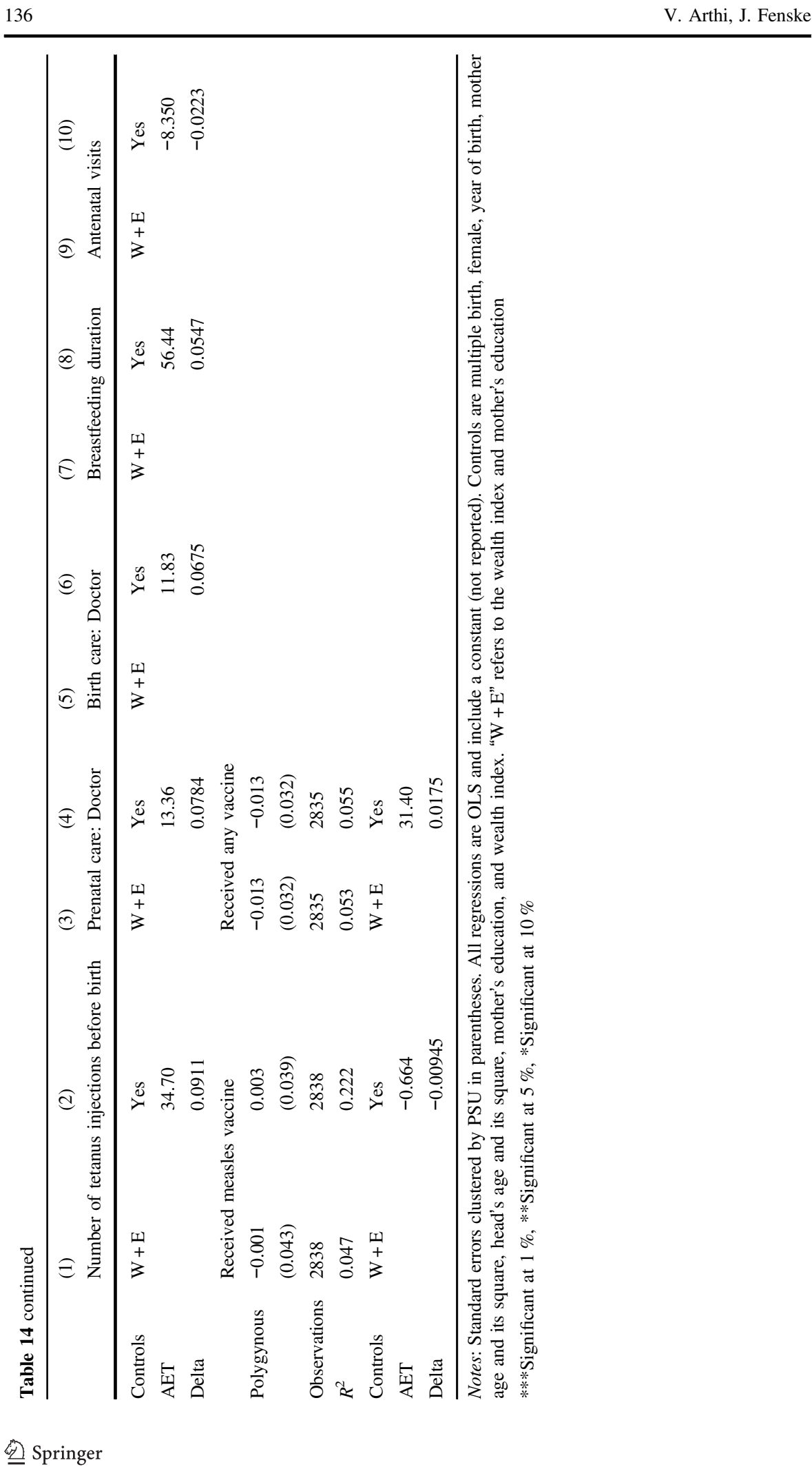




\section{References}

Aaby, P., Bukh, J., Lisse, I. M., \& Smits, A. (1983a). Spacing, crowding, and child mortality in GuineaBissau. The Lancet, 322(8342), 161.

Aaby, P., Bukh, J., Lisse, I. M., \& Smits, A. J. (1983b). Measles mortality, state of nutrition, and family structure: A community study from Guinea-Bissau. Journal of infectious diseases, 147(4), 693-701.

Aaby, P., Bukh, J., Lisse, I. M., \& Smits, A. J. (1984). Overcrowding and intensive exposure as determinants of measles mortality. American journal of epidemiology, 120(1), 49-63.

Achebe, C. (1958). Things fall apart. William Heinemann.

Agarwal, B. (1997). "Bargaining" and gender relations: Within and beyond the household. Feminist Economics, 3(1), 1-51.

Akresh, R., Chen, J. J., \& Moore, C. T. (2012). Productive efficiency and the scope for cooperation in polygynous households. American Journal of Agricultural Economics, 94(2), 395-401.

Akresh, R., Chen, J. J., \& Moore, C. T. (2016). Altruism, cooperation, and efficiency: Agricultural production in polygynous households. Economic Development and Cultural Change, 64(4), 661-696.

Almond, D., \& Currie, J. (2011). Human capital development before age five. In O. Ashenfelter, \& D. Card (Eds.), Handbook of labor economics (pp. 1315-1486). Amsterdam: North-Holland. Vol. 4, Part B.

Almond, D., Hoynes, H. W., \& Schanzenbach, D. W. (2011). Inside the war on poverty: The impact of food stamps on birth outcomes. The Review of Economics and Statistics, 93(2), 387-403.

Altonji, J. G., Elder, T. E., \& Taber, C. R. (2005). Selection on observed and unobserved variables: Assessing the effectiveness of catholic schools. Journal of Political Economy, 113(1), 151-184.

Amadiume, I. (1987). Male daughters, female husbands: Gender and sex in an African society. Zed Books.

Amankwaa, A. A. (1996). Prior and proximate causes of infant survival in Ghana, with special attention to polygyny. Journal of Biosocial Science, 28(03), 281-295.

Amey, F. K. (2002). Polygyny and child survival in West Africa. Social biology, 49(1-2), 74-89.

Angrist, J. D. and Pischke, J.-S. (2009). Mostly harmless econometrics: An empiricist's companion. Princeton University Press.

Arthi, V., \& Fenske, J. (2016). Intra-household labor allocation in colonial Nigeria. Explorations in Economic History, 60, 69-92.

Asakitikpi, A. E. (2008). Born to die: The Ogbanje phenomenon and its implication on childhood mortality in southern Nigeria. Anthropologist, 10(1), 59-63.

Bailey, R. E., Hatton, T. J., \& Inwood, K. (2016). Health, height, and the household at the turn of the twentieth century. Economic History Review, 69(1), 35-53.

Banerjee, A., Duflo, E., Postel-Vinay, G., \& Watts, T. (2010). Long-run health impacts of income shocks: Wine and Phylloxera in Nineteenth Century France. Review of Economics and Statistics, 92(4), 714-728.

Barker, D. J., \& Osmond, C. (1986). Infant mortality, childhood nutrition, and ischaemic heart disease in England and Wales. The Lancet, 1(8489), 1077-1081.

Barreca, A., Clay, K., Deschenes, O., Greenstone, M., \& Shapiro, J. S. (2016). Adapting to climate change: The remarkable decline in the US temperature-mortality relationship over the twentieth century. Journal of Political Economy, 124(1), 105-159.

Basden, G. T. (1921). Among the Ibos of Nigeria: An account of the curious \& interesting habits, customs, $\&$ beliefs of a little known african people by one who has for many years lived amongst them on close \& intimate terms. London: JB Lippincott Company.

Basden, G. T. (1938). Niger Ibos. Seeley, Service.

Bellows, J., \& Miguel, E. (2009). War and local collective action in Sierra Leone. Journal of Public Economics, 93(11), 1144-1157.

Bhalotra, S. (2010). Fatal fluctuations? Cyclicality in infant mortality in India. Journal of Development Economics, 93(1), 7-19.

Black, S. E., Devereux, P. J., \& Salvanes, K. G. (2005). The more the merrier? The effect of family size and birth order on children's education. The Quarterly Journal of Economics, 120(2), 669-700.

Bove, R., \& Valeggia, C. (2009). Polygyny and women's health in sub-Saharan Africa. Social science \& medicine, 68(1), 21-29.

Bozzoli, C., Deaton, A. S., \& Quintana-Domeque, C. (2009). Adult height and childhood disease. Demography, 46(4), 647-669. 
Brahmbhatt, H., Bishai, D., Wabwire-Mangen, F., Kigozi, G., Wawer, M., Gray, R. H., Group, T. R. P. G. P., Kidagovu, M., Kiwanuka, N., Lutalo, T., et al. (2002). Polygyny, maternal HIV status and child survival: Rakai, Uganda. Social science \& medicine, 55(4), 585-592.

Browning, M. (1992). Children and household economic behavior. Journal of Economic Literature, 30(3), 1434-1475.

Browning, M., Chiappori, P.-A., and Weiss, Y. (2014). Economics of the Family. New York: Cambridge University Press.

Burgess, R., Deschenes, O., Donaldson, D., \& Greenstone, M. (2014). The unequal effects of weather and climate change: Evidence from mortality in India. Cambridge, MA: Massachusetts Institute of Technology, Department of Economics. Manuscript.

Cage, R., \& Foster, J. (2002). Overcrowding and infant mortality: A tale of two cities. Scottish Journal of Political Economy, 49(2), 129-149.

Case, A. and Deaton, A. S. (2003). Consumption, health, gender, and poverty. World Bank Policy Research Working Paper 3020.

Case, A., \& Deaton, A. S. (2005). Health and wealth among the poor: India and South Africa compared. American Economic Review Papers \& Proceedings, 95(2), 229-233.

Cebu Study Team (1992). A child health production function estimated from longitudinal data. Journal of Development Economics, 38, 323-351.

Chetty, R., Hendren, N., and Katz, L. F. (2015). The effects of exposure to better neighborhoods on children: New evidence from the moving to opportunity experiment. NBER Working Paper No. 21156.

Coffey, D., Khera, R., and Spears, D. (2014). Women's status and children's height in India: evidence from joint rural households. Mimeo.

Cutler, D., Deaton, A. S., \& Lleras-Muney, A. (2006). The determinants of mortality. Journal of Economic Perspectives, 20(3), 97-120.

Dauphin, A. (2013). The role of polygyny in the intrahousehold efficienccy of agricultural production in West Africa. CIRPEE working paper 13-23.

Dauphin, A., Fortin, B., and Lacroix, G. (2010). Is behavior rational inside polygamous households? Mimeo.

Dauphin, A., Fortin, B., and Lacroix, G. (2015). How falsifiable is the collective model? A new test with an application to monogamous and bigamous households in Burkina Faso. IZA discussion paper no. 9002.

De La Croix, D. and Mariani, F. (2015). From polygyny to serial monogamy: A Unified Theory of Marriage Institutions. The Review of Economic Studies, in press, 82(2), 565-607.

Deaton, A. (2009). Instuments of development: randomization in the tropics, and the search for the elusive keys to economic development. NBER Working Paper No. 14690.

Deaton, A. and Cartwright, N. (2016). Understanding and misunderstanding randomized controlled trials. NBER Working Paper No. 22595.

Deaton, A. S. (1989). Looking for boy-girl descrimination in household expenditure data. The World Bank Economic Review, 3(1), 1-15.

Deaton, A. S. (1997). The anaysis of household surveys: A microeconometric approach to development policy. Baltimore: Johns Hopkins Uiversity Press.

Deaton, A. S. (2003). Health, inequality, and economic development. Journal of Economic Literature, 41, $113-158$.

Deaton, A. S. (2007). Height, health, and development. Proceedings of the National Academy of Sciences, 104(33), 13232-13237.

Deaton, A. S. (2008a). Height, health, and inequality: The distribution of adult heights in India. American Economic Review Papers \& Proceedings, 98(2), 468-474.

Deaton, A. S. (2008b). Income, health, and well-being around the world: Evidence from the Gallup World Poll. Journal of Economic Perspectives, 22(2), 53-72.

Deaton, A. S. (2012). The financial crisis and the well-being of Americans. Oxford Economic Papers, 64, $1-26$.

Deaton, A. S., \& Lubotsky, D. (2003). Mortality, inequality and race in American cities and states. Social Science \& Medicine, 56, 1139-1153.

Deaton, A. S., \& Muellbauer, J. (1986). On measuring child costs: With applications to poor countries. Journal of Political Economy, 94(4), 720-744.

Deaton, A. S., \& Paxson, C. (1998). Economies of scale, household size, and the demand for food. Journal of Political Economy, 106(5), 897-930. 
Deaton, A. S., Ruiz-Castillo, J., \& Thomas, D. (1989). The influence of household composition on household expenditure patterns: Theory and Spanish evidence. Journal of Political Economy, 97(1), 179-200.

Defo, B. K. (1996). Areal and socioeconomic differentials in infant and child mortality in Cameroon. Social Science \& Medicine, 42(3), 399-420.

Delaney, L., McGovern, M., \& Smith, J. P. (2011). From Angela's ashes to the Celtic tiger: Early life conditions and adult health in Ireland. Journal of Health Economics, 30, 1-10.

Desai, S. (1992). Children at risk: The role of family structure in Latin America and West Africa. The Population and Development Review, 18(4), 689-717.

Doepke, M., Tertilt, M., \& Voena, A. (2012). The economics and politics of women's rights. Annual Review of Economics, 4, 339-372.

Duflo, E. and Udry, C. (2004). Intrahousehold resource allocation in Cote d'Ivoire: Social norms, separate accounts and consumption choices. National Bureau of Economic Research Working Paper w10498.

Duquette, N. J. (2014). Revealing the relationship between ship crowding and slave mortality. Journal of Economic History, 74(2), 535-552.

Ebigbo, P., \& Chukudebelu, W. (1979). Child spacing and child mortality among Nigerian Igbos. International Journal of Gynaecology and Obstetrics: the ocial organ of the International Federation of Gynaecology and Obstetrics, 18(5), 372-374.

Egboh, E. O. (1972). Polygamy in Iboland (South-Eastern Nigeria) With special reference to polygamy practice among Christian Ibos. Civilisations, 22(3), 431-444.

Elender, F., Bentham, G., \& Langford, I. (1998). Tuberculosis mortality in England and Wales during 1982-1992: its association with poverty, ethnicity, and AIDS. Social Science and Medicine, 46(6), 673-681.

Eli, S. (2015). Income effect on health: Evidence from Union Army pensions. Journal of Economic History, 75(2), 448-478.

Ferreira, A., Leopoldo, J., \& Alves Waldman, E. (2001). The impact of AIDS, immigration and housing overcrowding on tuberculosis deaths in Sao Paulo, Brazil, 1994-1998. Social Science and Medicine, 52, 1071-1080.

Fishback, P., \& Thomasson, M. A. (2014). Hard times in the land of plenty: The effect on income and disability later in life for people born during the great depression. Explorations in Economic History, 54, 64-78.

Gage, A. J. (1997). Familial and socioeconomic influences on children's well-being: An examination of preschool children in Kenya. Social Science \& Medicine, 45(12), 1811-1828.

Gailey, H. A. (1970). The road to Aba: a study of British administrative policy in Eastern Nigeria. New York: New York University Press.

Garenne, M., \& Aaby, P. (1990). Pattern of exposure and measles mortality in Senegal. Journal of Infectious Diseases, 161(6), 1088-1094.

Gibson, M. A., \& Mace, R. (2007). Polygyny, reproductive success and child health in rural Ethiopia: Why marry a married man? Journal of Biosocial Science, 39(02), 287-300.

Goux, D., \& Maurin, E. (2005). The effect of overcrowded housing on children's performance at school. Journal of Public Economics, 89, 797-819.

Green, M. M. (1964). Ibo village affairs, Praeger.

Grossbard, S. (2014). The marriage motive: A price theory of marriage. New York: Springer.

Gyimah, S. O. (2003). Interaction effects of maternal education and household facilities on childhood diarrhea in sub-Saharan Africa: The case of Ghana. Journal of Health and Population in Developing Countries, 1-17.

Gyimah, S. O. (2009). Polygynous marital structure and child survivorship in sub-Saharan Africa: Some empirical evidence from Ghana. Social science \& medicine, 68(2), 334-342.

Hadley, C. (2005). Is polygyny a risk factor for poor growth performance among Tanzanian agropastoralists? American Journal of Physical Anthropology, 126(4), 471-480.

Han, J. and Foltz, J. D. (2015). Polygyny: Cooperation vs competition among wives and child nutrition. Mimeo.

Hauck, H. M. (1963). Child mortality in Awo Omamma, Eastern Nigeria. BJOG: AnInternational Journal of Obstetrics \& Gynaecology, 70(6), 1076-1080.

Heath, K. M., \& Hadley, C. (1998). Dichotomous male reproductive strategies in a polygynous human society: Mating versus parental effort. Current Anthropology, 39(3), 369-374.

Heckman, J. (1990). Varieties of selection bias. The American Economic Review, 80(2), 313-318.

Heckman, J. J. (1979). Sample selection bias as a specification error. Econometrica: Journal of the Econometric Society, 47(1), 153-161. 
Heckman, J. J. (2007). The economics, technology, and neuroscience of human capability formation. Proceedings of the National Academy of Sciences, 104(33), 13250-13255.

Henderson, H. K. (1969). Ritual roles of women in Onitsha Ibo society. Berkeley, CA: University of California. $\mathrm{PhD}$ thesis.

Henderson, R. N. (1972). The king in every man: evolutionary trends in Onitsha Ibo society and culture. New Haven: Yale University Press.

Henderson, R. N. and Henderson, H. K. (1966). An outline of traditional Onitsha Ibo socialization. Ibadan: Number 5. Institute of Education, University of Ibadan.

Ilika, A. L. (2005). Women's perception of partner violence in a rural Igbo community. African Journal of Reproductive Health, 9(3), 77-88.

Izugbara, C. O. (2000). Women's understanding of factors affecting their reproductive health in a rural Ngwa community. African Journal of Reproductive Health, 4(2), 62-68.

Kahneman, D., \& Deaton, A. S. (2010). High income improves evaluation of life but not emotional wellbeing. Proceedings of the National Academy of Sciences, 107(38), 16489-16493.

Kazianga, H. and Klonner, S. (2006). The intra-household economics of polygyny: Fertility and child mortality in rural Mali. Available at SSRN 923095.

Kazianga, H. and Wahhaj, Z. (2016). Intra-household resource allocation and familial ties. CSAE Working Paper WPS/2016-06.

Kingdon, G. (2005). Where has all the bias gone? Detecting gender bias in the intrahousehold allocation of educational expenditure. Economic Development and Cultural Change, 53(2), 409-451.

Kudamatsu, M. (2012). Has democratization reduced infant mortality in Sub-Saharan Africa? Evidence from Micro Data. Journal of the European Economic Association, 10(6), 1294-1317.

Kudamatsu, M., Persson, T., and Strömberg, D. (2012). Weather and infant mortality in Africa. CEPR Discussion Paper No. DP9222.

Leith-Ross, S. (1965). African women: a study of the Ibo of Nigeria. London: Routledge \& Kegan Paul.

Lucas, D., \& Ukaegbu, A. (1977). Other limits of acceptable family size in southern nigeria. Journal of biosocial science, 9(01), 73-81.

Martin, S. M. (2006). Palm oil and protest: An economic history of the Ngwa region, south-eastern Nigeria, 1800-1980. Cambridge: Cambridge University Press.

Nwoye, A. (2007). The practice of interventive polygamy in two regions of Africa: Background, theory and techniques. Dialectical anthropology, 31(4), 383-421.

Nzewi, E. (2001). Malevolent ogbanje: recurrent reincarnation or sickle cell disease? Social Science \& Medicine, 52(9), 1403-1416.

Ó Gráda, C. (2011). Fetal origins, childhood development, and famine: A bibliography and literature review. University College Dublin Centre for Economic Research Working Paper Series WP11/28.

Okemgbo, C. N., Omideyi, A. K., and Odimegwu, C. O. (2002). Prevalence, patterns and correlates of domestic violence in selected Igbo communities of Imo State, Nigeria. African Journal of Reproductive Health, 6(2), 101-114.

Okere, L. C. et al. (1979). Socio-economic and cultural aspects of food and food habits in rural Igboland. Ph.D. Thesis, State University of New York at Buffalo.

Okonjo, K. (1975). The role of women in the development of culture in Nigeria. In Ruby Rohrlich-Leavitt (Ed.), Women cross-culturally: Change and challenge, The Hague: Mouton Publishers 31-40.

Omariba, D., \& Boyle, M. H. (2007). Family structure and child mortality in Sub-Saharan Africa: Crossnational effects of polygyny. Journal of Marriage and Family, 69(2), 528-543.

Oster, E. (2016). Unobservable selection and coefficient stability: Theory and validation. Journal of Business Economics and Statistics, in press.

Ottenberg, P. V. (1982). Marriage relationships in the double descent system of the Afikpo Ibo of Southeastern Nigeria. Ann Arbor: University Microfilms.

Pilla, L. and Dantas, J. A. (2016). Intra-household nutritional dynamics: A cross-sectional study of Maasai communities in Kenya. Qualitative Health Research, 26(6), 793-806

Rossi, P. (2015). Strategic choices in polygamous households: Theory and evidence from Senegal. Mimeo.

Sellen, D. W. (1999). Polygyny and child growth in a traditional pastoral society. Human Nature, 10(4), 329-371.

Smith-Greenway, E., \& Trinitapoli, J. (2014). Polygynous contexts, family structure, and infant mortality in Sub-Saharan Africa. Demography, 51, 341-366.

Stephenson, R., Baschieri, A., Clements, S., Hennink, M., \& Madise, N. (2006). Contextual influences on the use of health facilities for childbirth in Africa. American Journal of Public Health, 96(1), 84-93.

Strassmann, B. I. (1997). Polygyny as a risk factor for child mortality among the dogon. Current Anthropology, 38(4), 688-695. 
Subramanian, S., \& Deaton, A. S. (1991). Gender effects in Indian consumption patterns. Sarvekshana, 14 (4), 1-12.

Subramanian, S., \& Deaton, A. S. (1996). The demand for food and calories. Journal of Political Economy, 104(1), 133-162.

Tertilt, M. (2005). Polygyny, fertility, and savings. Journal of Political Economy, 113(6), 1341-1371.

Thomas, N. W. (1913). Anthropological Report on the Ibo-speaking Peoples of Nigeria. London: Harrison and Sons.

Uche, C. (1985). The environment of infant and child mortality: A case study of Nigerian villages. Presented at the Annual Meeting of the Population Association of America, Boston, Massachusetts, March 28-30, 1985.

Uchendu, V. C. (1965). The Igbo of Southeast Nigeria. New York: Holt, Rinehart and Winston.

Ukaegbu, A. O. (1977). Fertility of women in polygynous unions in rural Eastern Nigeria. Journal of Marriage and the Family, 39(2), 397-404.

Ukwuani, F. A., Cornwell, G. T., \& Suchindran, C. M. (2002). Polygyny and child survival in Nigeria: Age-dependent effects. Journal of Population Research, 19(2), 155-171.

Wagner, N., \& Rieger, M. (2015). Polygyny and child growth: Evidence from twenty-six African countries. Feminist Economics, 21(2), 105-130.

Williamson, J. G. (1982). Was the Industrial Revolution woth it? Disamenities and death in 19th Century British towns. Explorations in Economic History, 19, 221-245.

Wood, D. (2003). Effect of child and family poverty on child health in the United States. Pediatrics, 112 (3), 707-711. 